Document downloaded from:

http://hdl.handle.net/10251/119594

This paper must be cited as:

Monzó Cárcel, PM.; Puttige, AR.; Acuña, J.; Mogensen, P.; Cazorla-Marín, A.; Rodríguez, J.; Montagud, C.... (2018). Numerical modeling of ground thermal response with borehole heat exchangers connected in parallel. Energy and Buildings. 172:371-384.

https://doi.org/10.1016/j.enbuild.2018.04.057

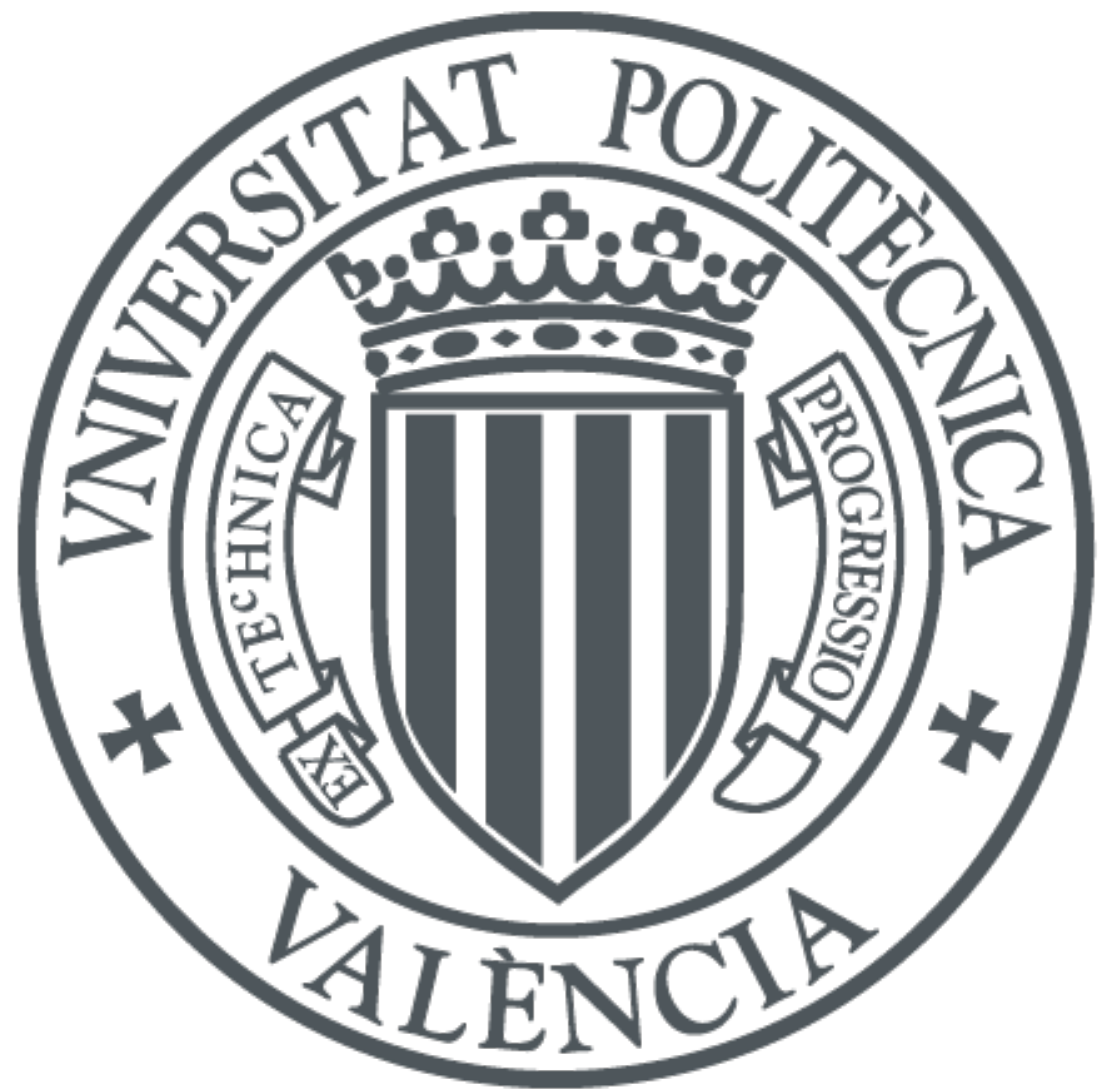

The final publication is available at

https://doi.org/10.1016/j.enbuild.2018.04.057

Copyright Elsevier

Additional Information 


\section{Numerical modeling of ground thermal response with borehole heat exchangers connected in parallel}

Patricia Monzóa ${ }^{a}$, Anjan Rao Puttige ${ }^{a}$, José Acuña ${ }^{a}$, Palne Mogensen ${ }^{a}$, Antonio Cazorlab ${ }^{b}$ Juan Rodriguez ${ }^{c}$, Carla Montagud ${ }^{b}$, Fernando Cerdeira ${ }^{d}$

a KTH Royal Institute of Technology, Brinellvägen 68, Stockholm 100 44, Sweden

b IUIIE - Instituto Universitario de Investigación en Ingeniería Energética, Universitat Politècnica de València, Camino de Vera s/n, Valencia 46022, Spain

c EnergyLab, Fonte das Abelleiras s/n, Campus Universidad de Vigo, Vigo 36310, Spain

d Universidad de Vigo, Maxwell 16, Vigo 36310, Spain

\section{Abstract}

With bore fields for energy extraction and injection, it is often necessary to predict the temperature response to heat loads for many years ahead. Mathematical methods, both analytical and numerical, with different degrees of sophistication, are employed. Often the g-function concept is used, in which the borehole wall is assumed to have a uniform temperature and the heat injected is constant over time. Due to the unavoidable thermal resistance between the borehole wall and the circulating fluid and with varying heat flux along the boreholes, the concept of uniform borehole wall temperature is violated, which distorts heat flow distribution between boreholes. This aspect has often been disregarded. This paper describes improvements applied to a previous numerical model approach. Improvements aim at taking into account the effect of thermal resistance between the fluid and the borehole wall. The model employs a highly conductive material (HCM) embedded in the boreholes and connected to an HCM bar above the ground surface. The small temperature difference occurring within the HCM allows the ground to naturally control the conditions at the wall of all boreholes and the heat flow distribution to the boreholes. The thermal resistance between the fluid and the borehole wall is taken into account in the model by inserting a thermally resistive layer at the borehole wall. Also, the borehole ends are given a hemispherical shape to reduce the fluctuations in the temperature gradients there. The improvements to the $\mathrm{HCM}$ model are reflected in a changed distribution of the heat flow to the different boreholes. Changes increase with the number of boreholes. The improvements to the HCM model are further illustrated by predicting fluid temperatures for measured variable daily loads of two monitored GCHP installations. Predictions deviate from measured values with a mean absolute error within 1.1 and $1.6 \mathrm{~K}$.

\section{Keywords}

Borehole heat exchanger; Numerical modeling; Monitoring; Fluid temperature prediction; Boundary condition 


\section{Abbreviations}

$\mathrm{BH}$, borehole;

EED, earth energy designer;

EHCM, enhanced highly conductive material;

FDM, finite difference method;

FEM, finite element method;

FLS, finite line source;

GCHP, ground-coupled heat pump;

$\mathrm{GHE}$, ground heat exchanger;

GLHEPRO, ground loop heat exchanger professional;

HCM, highly conductive material;

MAE, mean absolute error;

$\mathrm{MBE}$, mean bias error;

RMSE, root mean square error;

SBM, superposition borehole model;

TRF, Temperature response function;

TRL, Thermally resistive layer

\section{Nomenclature}

$\alpha$ Thermal diffusivity ( $\left.\mathrm{m}^{2} / \mathrm{s}\right)$

B Borehole spacing $(\mathrm{m})$

$D$ Inactive upper part of the borehole $(\mathrm{m})$

$\delta$ Thickness of the thermally resistive layer $(\mathrm{m})$

$\mathrm{Fo}_{\mathrm{H}}$ Fourier number, with $\mathrm{H}$ as the characteristic length

$\mathrm{H}$ Total active borehole length (m)

$k$ Thermal conductivity $(\mathrm{W} /(\mathrm{m}-\mathrm{K}))$

$Q$ Heat flow (W)

$\bar{Q}$ Average heat flow (W) per borehole

$q$ Heat flow per unit length $(\mathrm{W} / \mathrm{m})$

$\bar{q}$ Average heat flow per unit length $(\mathrm{W} / \mathrm{m})$ per borehole 
$\mathrm{R}_{\mathrm{b}}$ Local GHE thermal resistance $((\mathrm{m}-\mathrm{K}) / \mathrm{W})$

$\mathrm{R}_{\mathrm{b}}$ * Effective GHE thermal resistance $((\mathrm{m}-\mathrm{K}) / \mathrm{W})$

$r_{b}$ Borehole radius $(m)$

t Time (s)

$t_{s} H^{2} / 9 \alpha(\mathrm{s})$ Characteristic time

T Temperature $\left({ }^{\circ} \mathrm{C}\right)$

\section{Subscripts}

bh Borehole

bw Borehole wall

g Undisturbed ground

\section{Introduction}

A conventional ground-coupled heat pump (GCHP) system consists of three main components: an indoor air or water circuit in the building, an outdoor heat carrier fluid circuit buried in the ground, and a heat pump. The advantage of using the ground as a heat source or sink derives from the fact that the ground temperature is relatively stable, higher during winter and lower during summer, as compared to the temperature of the outdoor air. The outdoor circuit is commonly a bore field, made up of a closedloop of vertical U-pipe heat exchangers buried in the ground, the ground heat exchangers (GHEs), normally connected in parallel. The outdoor circuit is designed to keep the inlet fluid temperature of the heat pump (outlet fluid temperature of the GHE) within specified operational limits as the ground supplies the intended energy demand of the building. To ensure a sustainable and high performance of the heat pump over the years, long-term prediction of the thermal response of the ground and the GHEs are required. Both numerical and analytical methods are utilized to predict the long-term response of the ground. Usually convective processes in the ground are disregarded because of their irregular nature and only thermal conduction is considered. The thermal conductivity of the ground is known from e.g. thermal response tests.

When modeling GHEs connected in parallel, two simultaneous boundary conditions are usually applied: a uniform temperature at all borehole walls and a defined total heat flow to the bore field. The assumption of a uniform borehole wall temperature has its foundation on the parallel hydraulic connection of the boreholes and on the small temperature difference between incoming and outgoing heat carrier fluid. Because of the thermal resistance between the heat carrier fluid and the borehole wall and the fact that the heat flux increases towards the borehole ends (bottom and top), the condition at the borehole wall differs from the assumption of a uniform temperature along the borehole wall. 
This paper describes improvements applied to the numerical approach reported in Monzó et al. [23] in order to correct the representation of the temperature and heat flux profiles at the borehole wall. The model presented in this paper is utilized to generate the long-term temperature response for multiple bore field configurations when a constant total heat flow is injected into the bore field. The long-term temperature response obtained from the model described in this paper is illustrated along with the long-term temperature response obtained from the previous version of the model and other state of the art solutions. The improved model is also utilized to compute daily fluid temperature predictions for variable measured daily loads of two monitored GCHP installations. The predicted daily fluid temperatures are compared with the corresponding measured fluid temperatures and with the predicted values obtained from the previous numerical model.

\section{Background}

The energy demand of a building is characterized by a variable (heating and/or cooling) load profile. Subsequently, if using a GCHP with vertical boreholes, a bore field is also subjected to a variable load profile (heat extraction and/or injection). Commercial design software programs widely in use, such as Earth Energy Designer (EED) [14] and Ground Loop Heat Exchanger Professional (GLHEPRO) [20], are capable of easily predicting the temperature response due to a variable load profile (repeated over the user's simulation time with a period of one year) for hundreds of bore field configurations, normally contained in their pre-calculated libraries. Due to the linear nature of heat conduction, the thermal response of the bore field to a variable load, the procedure implemented in these software programs, is based on a sequential superposition of the stepwise variable loads over the characteristic temperature response of the bore field, traditionally called the g-function.

The g-function is a dimensionless temperature response factor that relates the change in temperature over time at the borehole wall $\left(T_{b w}\right)$ from its undisturbed value $\left(T_{g}\right)$ when a constant total heat load $\left(\overline{\mathrm{q}} \times \mathrm{H}_{)}\right)$is injected into the bore field. This response is obtained from the assumption that pure heat conduction occurs in a homogenous surrounding ground medium with the definition of constant temperature (undisturbed value) at the boundaries of the surrounding ground. The g-function is usually represented over a non-dimensional time and is unique for given geometrical aspect ratios of the borehole field. The g-function is mathematically defined in Eq. (1)

equation(1)

$\mathrm{T}_{\mathrm{bw}}-\mathrm{T}_{\mathrm{g}}=\frac{\bar{q}}{2 \pi \mathrm{k}} \mathrm{g}\left(\frac{\mathrm{t}}{\mathrm{t}_{\mathrm{s}}}, \frac{\mathrm{r}_{\mathrm{b}}}{\mathrm{H}}, \frac{\mathrm{B}}{\mathrm{H}}, \frac{\mathrm{D}}{\mathrm{H}}\right)$

One important aspect of the g-function generation is the definition of the boundary condition at the borehole wall as discussed in Bernier [2]. Eskilson [10] introduced the concept of the g-function, in which the definition of the boundary condition at the borehole wall was carefully studied. Three types of boundary conditions at the borehole 
wall were considered and implemented in Eskilson's 3D-finite difference method (FDM) computing program (SBM-Superposition Borehole Model). Cimmino and Bernier [6] provided a comprehensive categorization of these different types of boundary conditions. The first boundary condition assumes an equal heat distribution among the boreholes and a uniform heat flux along their depth. The second boundary condition refers to an average borehole wall temperature in all the boreholes. In this second type of boundary condition the heat extraction rate is different in each borehole but it is uniformly distributed along each borehole depth. The third type of boundary condition considers that the temperature along the borehole walls is uniform and equal in all boreholes. Simultaneously, the total heat flow in all the boreholes should be equal to the total heat flow transferred to the bore field at any given time, which should be constant for the g-function generation. This third boundary condition was Eskilson's preference for the g-function generation.

The assumption of a uniform temperature along the borehole length can be justified with the small temperature difference between incoming and outgoing heat carrier fluid in U-pipe GHEs at high flow rates [16]. The second assumption, the same borehole wall temperature in all boreholes, is justified by the hydraulic and thermal connections that occur when boreholes are connected in parallel. The uniform borehole wall temperature condition is widely accepted as a good representation of the thermal process at the borehole wall. Therefore, g-functions were generated for several bore field configurations and implemented in libraries of commercial design tools. Since then, these temperature response factors by Eskilson have been considered as benchmark solutions.

During the last two decades, exhaustive research activities have been dedicated to analytical solutions for the g-functions because of their flexibility, especially in design and optimization tasks. The efforts have been focused on finding accurate and fast computational methods for the generation of g-functions. Early efforts were dedicated to making the analytical solution practical for engineering purposes. In this direction, simpler expressions of the FLS solution to calculate the mean borehole wall temperature were investigated by Eskilson [11], Zeng et al. [29], Lamarche and Beauchamp [17], and Claesson and Javed [8]. The simplifications proposed by Lamarche and Beauchamp [17] and Claesson and Javed [8] could both rapidly solve the FLS problem. However, as shown by Lee and Lam [19] and Fossa [12], the g-function obtained from pure FLS approaches, which assumes that the heat flux is constant at the borehole wall, overestimates the g-function as compared to the one obtained from the SBM model with the uniform borehole wall temperature condition. These deviations increase with the number of boreholes and time, which is attributed to the definition of the boundary condition at the borehole wall.

Lately, research efforts have been focused on the representation of the boundary condition at the borehole wall when using the FLS solution. Cimmino and Bernier [6]proposed a semi-analytical solution in which the borehole is modeled as a series of segments. The uniform temperature condition at the borehole wall is fulfilled 
with the definition of an equal temperature in all the segments in all boreholes at every given time. The borehole wall temperature at each segment is calculated from a spatial and temporal superposition of the FLS solution. This approach is employed to model boreholes with different lengths and buried depths in Cimmino and Bernier [6], implemented in a pre-processor tool [7]. A similar concept was used and extended to inclined boreholes by Lazzarotto [18].

An experimental setup was built to measure the thermal response at the borehole wall for a scaled single borehole in a sand tank during a sufficient time span to reach steady state condition, as reported in Cimmino and Bernier [5]. The non-dimensional borehole wall temperature measurements were compared to non-dimensional temperature response obtained from the approach in Cimmino and Bernier [6] with a uniform borehole temperature condition. It was reported that, in general, the theoretical solution tends to underestimate the experimental response. The deviations started when $\ln \left(t / t_{s}\right)=-3$ and increased with time. A $4.7 \%$ difference was observed at $\ln \left(t / t_{s}\right)=1.92$. However, the theoretical response was within the uncertainty threshold of the experiment. Differences were partly attributed to air temperature variations above the top surface of the sand tank, which differed from a controlled temperature boundary condition at the top surface as defined in the theoretical model.

Concerning numerical methods, during the last years, researchers also tried to develop solutions that are capable of providing an accurate and detailed description of the thermal process in bore fields. Zanchini et al. [28] developed a 2D axisymmetric model with a constant heat flux boundary condition at the borehole wall. Priarone and Fossa [25] developed a model in COMSOL Multiphysics ${ }^{\circledR}$, in which temperature response factors for the single borehole are generated for different boundary conditions, defined as constant heat flux boundary condition and constant borehole wall temperature boundary condition. Priarone and Fossa [24] extended their model for the single borehole to predict ground temperature response, with a similar concept as proposed in Monzó et al. [23].

As pointed out by Lee and Lam [19], most GHE models are based on a constant heat flux or uniform temperature approach to model the response of the surrounding ground and on a fixed GHE thermal resistance that accounts for the heat transfer inside of the GHE. However, the coupling effect between the boreholes and the surrounding ground may not result in either a uniform temperature or a constant heat flux along the borehole length. Thus, efforts have also been focused on the development of more detailed models that take into account the response of the GHE along the borehole depth, coupling it to the response of the ground.

Lee and Lam [19] proposed a 3D implicit FDM that modeled the heat transfer inside the borehole with a 3D FDM under a quasi-steady state condition. The heat transfer in the surrounding ground was also modeled with a 3D FDM with a rectangular coordinate system in which boreholes are represented by square columns. These two solutions were coupled and solved iteratively at each time step. Temperature profiles of the fluid along upward and downward pipes and of the borehole wall were obtained for a single 
borehole $\left(r_{b} / H=0.0005\right)$ under continuous heat injection for a 10 year-period. The temperature profile at the borehole wall showed that the maximum temperature occurred near the top edge of the borehole, in contrast to the maximum value observed at mid-height borehole when results were obtained from a pure FLS solution, as proposed by Zeng et al. [30]. Besides the edge effect at borehole ends, a temperature difference of $0.2 \mathrm{~K}$ between the upper and downward part of the borehole wall was found in Lee and Lam [19]. A slight temperature difference in the averaged-over-thedepth fluid temperature at the upward and downward pipes was also observed in Lee and Lam [19], being around $0.7 \mathrm{~K}$.

Recently, Cimmino [4] proposed a semi-analytical solution that accounts for the axial variation of temperature and heat rates at the borehole wall for single U-pipes connected in parallel, due to the thermal interaction between the fluid and the borehole wall. In this model, an analytical approach of the heat transfer process between the fluid and the borehole wall is coupled to a system of equations that solve temperature and heat transfer rate, based on the aforementioned procedure by Cimmino and Bernier [6]. This model is solved for an equal inlet fluid temperature in all boreholes. The effect of the GHE thermal resistance and the fluid flow rate in temperature response functions are studied for a total constant heat flow and given geometrical aspect ratios of single and of $4 \times 4$ bore fields. No relevant effects in relation to the fluid flow rate were observed for particular geometrical aspect ratios on the steady state values of the temperature response functions. Simulations were performed at steady state for a ground with a thermal conductivity equal to $2 \mathrm{~W} /(\mathrm{m}-\mathrm{K})$ and for a GHE with a local thermal resistance of $0.1(\mathrm{~m}-\mathrm{K}) / \mathrm{W}$, which showed that a model with uniform borehole wall temperature underestimate the steady-state g-function value by $2.1 \%$ for a $4 \times 4$ bore field and by $4.3 \%$ for a $10 \times 10$ bore field. An extended model that accounts for fluid and borehole wall interaction in multiple U-pipes is proposed in [3]. Independent, parallel and in series connection of U-pipes in a single borehole are investigated in this work. For the case of double U-pipes with parallel connection in a single borehole with given geometrical aspect ratios and a fluid flow rate of $0.2 \mathrm{~kg} / \mathrm{s}$, the fluid temperature along the downward and upward pipes were shown along with the temperature at the borehole wall after 10 years of continuous heat extraction. By analyzing them, it could be observed that an average between the downward and upward fluid temperatures showed a small temperature change along the borehole depth. The fluid temperature change increased with depth, as heat is extracted, being less than $0.1 \mathrm{~K}$ difference between the temperature at the upper and lower part. Besides the edge effects at the top and bottom parts of the borehole, near the ends of the borehole, a small temperature difference between the upper and lower part of the borehole can be observed. The temperature difference is less than $0.1 \mathrm{~K}$, which increased with depth.

Field measurements of fluid temperatures along the downward and upward pipes in Upipe GHEs and for relatively high flow rates, reported in Acuña [1] showed a small temperature gradient when the fluid temperature (down and up flow) is averaged along the borehole depth. 
As supported by theoretical and observational investigations, the temperature gradient along the borehole depth is small. Therefore, the assumption of a uniform fluid temperature along the borehole depth can be accepted as representative for typical Upipe GHEs, with typical borehole lengths and high flow rates.

\section{Numerical model}

The numerical approach described in Monzó et al. [23] employed the concept of a fictitious highly conductive material (HCM) to model the response of the ground when a total heat flow is imposed in the bore field. This model was named the HCM model. In the past and the present study, the ground is considered as a homogenous and isotropic medium with constant and temperature independent thermo-physical properties. Thus, the heat transfer in the ground is modeled as a pure heat conduction process. The HCM model consisted of a fictitious HCM embedded in the boreholes and of a bar of the same $\mathrm{HCM}$ located somewhat above the top surface to which the boreholes are physically connected. The connection of the boreholes to the bar is carried out to represent the parallel thermal connection when the bore field comprises more than one borehole. Auxiliary cone elements of HCM are used to represent the inactive upper part of the boreholes so that the top surface of the active borehole is connected with the bar. A typical thermal conductivity for the HCM may be $10^{10} \mathrm{~W} /(\mathrm{m}-\mathrm{K})$. The high value of the thermal conductivity of the HCM material creates a very small temperature difference within the cylinders embedded inside the boreholes so that by means of applying the total bore field heat flow at one spot of the HCM bar, the heat flow is distributed through the $\mathrm{HCM}$ to each borehole according to the temperature response of the surrounding ground.

The main advantage of the use of the HCM to model the response of the ground with bore fields is a substantial simplification of the computational calculation in two aspects. The first aspect is the simplification of the thermal response of the GHE through the use of the HCM. Modeling of the heat transfer in each of the components in the GHE (fluid, grouting, piping) is made simpler through the use of the $\mathrm{HCM}$, which imitates the averaged-over-depth temperature response of the fluid. The second aspect is that tedious iterative computations to calculate the heat flow distribution among the boreholes and along the borehole depth are avoided as ground response naturally controls the heat flow through the borehole walls.

The temperature and heat flux distributions along the boreholes walls were studied in Monzó et al. [23]. The temperature was uniform along the borehole wall and equal in all boreholes. The heat flow in each borehole was distributed according to the thermal conditions of the ground surrounding in each borehole. The heat flux profile along the borehole length presented much higher values at the top and bottom of the borehole than at the remaining borehole length. The comparison of temperature response functions with reference solutions based on uniform borehole wall temperature resulted in similar results as compared to the response from the HCM model. However, the high temperature gradients occuring near the edges of the borehole and the size of the elements of the mesh caused unexpected high heat flux values at the borehole edges 
as compared with Cimmino [4]. Further investigation was carried out to identify the cause of the high heat flux values.

Thus, the observations of unexpected high heat flux values resulted in the revision of the features of our mathematical approach, such as time step, mesh or geometry and the definition in mathematical modeling of the heat transfer process occurring between the fluid and the borehole wall. The inevitable thermal resistance occurring between the fluid and the borehole wall results in a temperature drop between the fluid and the borehole wall, which becomes higher at the ends of the boreholes where the heat flux is higher. Thus, the temperature profile along the borehole wall moves away from the assumption of an isothermal borehole wall when local heat flux variations are considered. Thus, a uniform temperature boundary condition at the borehole wall is not fully in agreement with the original boundary condition with a uniform fluid temperature. This aspect was disregarded in Eskilson's studies and is the subject of study in the present paper, which contributes to recent studies presented in Cimmino [4].

Thus, the improvements applied in the HCM model are intended to model the response of the ground according to original assumption of heat transfer process along the borehole wall (uniform temperature) and to correct the heat flux distribution through the borehole wall. As the HCM model, COMSOL Multiphysics ${ }^{\circledR}$, a numerical software based on the finite element method (FEM), is employed to develop the enhanced version of the HCM model. The numerical model that contains the improvements applied to the HCM model is named 'enhanced HCM model' and labeled EHCM model in the following sections.

The correction of the heat flux distribution through the borehole walls is accomplished by introducing a thin thermally resistive layer (TRL) between the HCM and the borehole wall. Thus, the thermal resistance between the fluid and the borehole wall is reproduced by the TRL located at the borehole wall. In COMSOL Multiphysics ${ }^{\circledR}$, the TRL is defined at the boundaries relative to the boreholes walls.The thickness and the thermal conductivity of the TRL are given as inputs to the model according to Eq. (2) and as a function of the value of the borehole radius and the GHE thermal resistance of interest. For instance, for a borehole radius $\left(r_{b}\right)$ of $0.07 \mathrm{~m}$ and a GHE thermal resistance $\left(R_{b}\right)$ equal to $0.1(\mathrm{~m}-\mathrm{K}) / \mathrm{W}$, its thermal conductivity corresponds to $0.159 \mathrm{~W} /(\mathrm{m}-\mathrm{K})$ for an arbitrary choice of $5 \mathrm{~mm}$ thickness of the TRL $\left(\delta_{\text {layer }}\right)$.

equation(2)

$\mathrm{R}_{\mathrm{b}}=\frac{\delta_{\text {layer }}}{2 \cdot \pi \cdot \mathrm{r}_{\mathrm{b}} \cdot \lambda_{\text {layer }}}$

To avoid strong heat flux gradients at the bottom ends of the boreholes, a hemispherical element is drawn at the bottom part of the borehole. It should also be noted that in the EHCM model, the use of TRL results in the temperature in the HCM to be equal to the fluid temperature and the temperature outside the thermally resistive layer to be equal to the borehole wall temperature. To avoid the transition region, a radial distance of 
$1.01 \times r_{b}$ is chosen for the evaluation of the borehole wall temperature and heat flux profiles, as shown in [26].

Taking advantage of heat transfer symmetries ocurring within the bore field, the computing domain is reduced to the greatest possible extent. Thus, the computing geometries of the $2 \times 3$ and $4 \times 4$ bore fields, studied in this paper, have been reduced to one quarter and one eighth, respectively, of the entire domain.

The meshing strategy is similar to the one utilized in Monzó et al. [23] with some improvements that have increased the accuracy and still keeping an acceptable computing time (around $8 \mathrm{~h}$ ) for g-function generation and less than $1 \%$ deviation on total heat flow calculations. As in the HCM model, the surrounding ground is split into several meshing regions for size elements refinement purposes. The mesh in the region surrounding the bore field comprises radial elements made up of triangular elements swept from the top layer below the inactive upper part of the bore field. The surrounding outward region next to the bore field is meshed with tetrahedral elements. Thetrahedral elements are also used to mesh the remaining domains: hemispherical elements at the bottom of the boreholes, an eighth hemispherical region downward the bore field and the remaining region downward the bore field region. The size of the elements is controlled in each meshing region. The closer the region is to the borehole edges, the finer the elements of the mesh. Thus, regions near the borehole edges comprise the finest mesh, increasing with distance. Free tetrahedral elements are also utilized in the HCM bar and the HCM embedded in the boreholes. The total number of elements in the mesh is around 200,000. The simulations of the EHCM model were performed on two computers, one with an Intel Core i7 $2.8 \mathrm{GHz}$ processor and 8GB RAM and another one with an Intel(C) Xeon(C) processor CPU E5-2620 at $2.00 \mathrm{GHz}$ (2 processors) with 32GB RAM.

\section{Generation of the temperature response function}

The pioneering work of Eskilson with the g-function approach is used as a benchmark in this paper. Similarly, to the g-function concept, the EHCM model is utilized to obtain the average borehole wall temperature in the bore field when a constant total heat flow is imposed in the bore field.

When the g-function concept was introduced, it was clearly stated as a formula to relate the temperature at the borehole wall and the heat extraction rate when either heat flux or temperature boundary conditions are defined at the borehole wall. However, in the numerical model described in this paper, the total constant heat flow defined as a heat rate across the boundaries on the HCM bar (Neumann boundary condition) differs somewhat from the definition of the boundary condition in the g-function concept (at the exact location at the borehole wall). Besides, it should be noted that in the EHCM model the temperature at the borehole wall is slightly different in each borehole, as ground conditions naturally control the heat flux distribution across borehole wall. This fact also differs from the assumption stated above that all the boreholes have the same borehole wall temperature. Thus, the total average bore field temperature results from 
the average borehole wall temperature along the borehole length in all boreholes. For this reason, the term "temperature response function" (TRF) is used in this paper to refer to the dimensionless temperature response of bore fields obtained from the EHCM model with a continuous total heat flow. When illustrating the results in Figs. 1, Fig. 7 ; Fig. 11 and 12and their analyses, both the TRF from the EHCM model and g-function solutions, are referred as TRF, as it is a more general term, along with an abbreviation tag relative to the source of their solution.

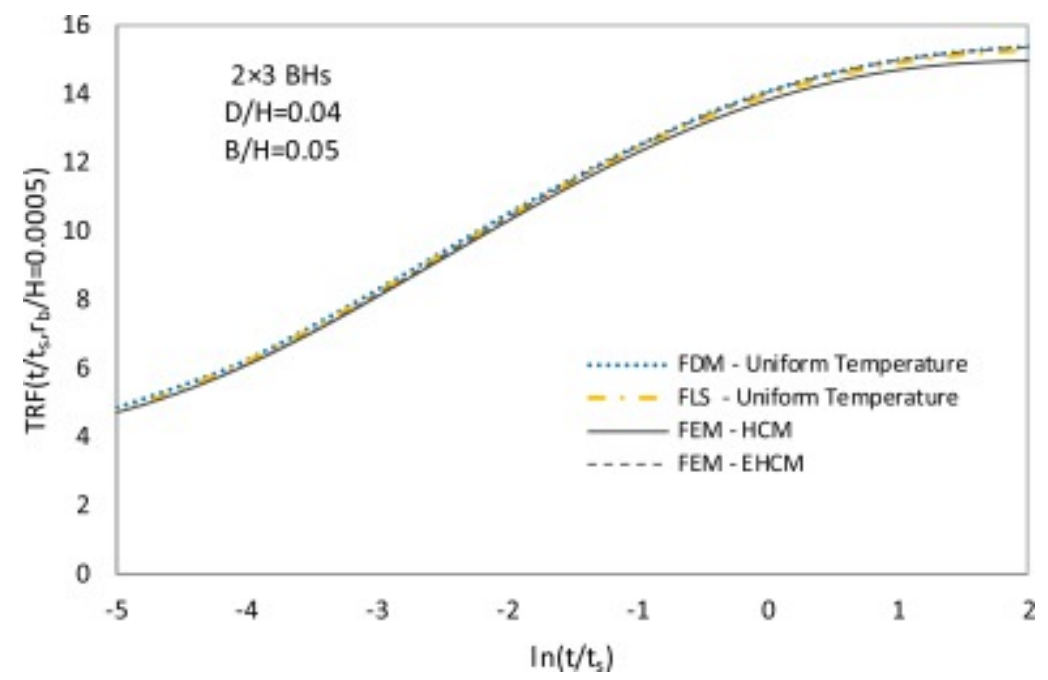

Fig. 1. TRFs for a $2 \times 3$ bore field (with $\mathrm{k}=3.5 \mathrm{~W} /(\mathrm{m}-\mathrm{K}) ; \mathrm{R}_{\mathrm{b}}=0.1(\mathrm{~m}-\mathrm{K}) / \mathrm{W}$ in the EHCM model).

TRFs for a $2 \times 3$ bore field and a $4 \times 4$ are obtained from the EHCM model, for a ground thermal conductivity of $3.5 \mathrm{~W} /(\mathrm{m}-\mathrm{K})$ and a GHE thermal resistance of $0.1(\mathrm{~m}-\mathrm{K}) / \mathrm{W}$. The TRF from the EHCM model is illustrated along with reference solutions in Figs. 1 and 7, respectively. The TRFs presented in Figs. 1 and 7 are labeled with an abbreviation that makes reference to the approach utilized (FDM, FEM or FLS) and to the boundary condition defined at the GHE. Reference solutions obtained from a uniform borehole wall temperature condition and equal in all the boreholes are tagged as "Uniform Temperature". The reference solution obtained from the commercial design tool ([14] or [20]) based on the SBM [11] is tagged as "FDM - Uniform Temperature". The reference solutions tagged as "FLS - Uniform Temperature" resulting from the semianalytical approach based on the FLS developed by Cimmino and Bernier [6]. The solutions resulting from the numerical HCM model presented in Monzó et al. [23] are tagged as "FEM - HCM". The solutions obtained from the EHCM model are tagged as "FEM - EHCM".

This paper also includes the analysis of the temperature and heat flux profiles along the boreholes walls resulting from the EHCM model for the aforementioned bore field geometries. These results demonstrate the differences on the thermal response between the original assumption (uniform fluid temperature) and the most-common accepted hypothesis (uniform borehole wall temperature). Moreover, the influence of the borehole thermal resistance on the thermal response of the ground at the borehole wall is also analyzed in this paper. 
It should be noted that an error related to the size of the surrounding domain of the GHEs was found in the results of the EHCM model presented in [26] and [27]. The corrected results and their corresponding analysis are presented in this paper.

\subsection{TRF for $2 \times 3$ bore field}

The TRF for a $2 \times 3$ bore field configuration obtained from the EHCM model is presented in Fig. 1 along with the aforementioned reference solutions.

In Fig. 1, at short times, differences between the TRFs resulting from the 'FEM - EHCM' and ' $\mathrm{FEM}-\mathrm{HCM}^{\prime}$ are very small. For instance, at $\ln \left(\mathrm{t} / \mathrm{t}_{\mathrm{s}}\right)=-4.5$ (90 days when $\mathrm{H}=100 \mathrm{~m}$ and $\alpha=1.58 \times 10^{-6} \mathrm{~m}^{2} / \mathrm{s}$ ) the TRF-'FEM - $\mathrm{HCM}^{\prime}$ underestimates the response as compared to the TRF- 'FEM - EHCM' by 0.01 units (0.2\%). However, the differences increase with time. The response from the ' $\mathrm{FEM}-\mathrm{HCM}^{\prime}$ is 0.27 units (1.8\%) lower than the response from the 'FEM-EHCM' when $\ln \left(\mathrm{t} / \mathrm{t}_{\mathrm{s}}\right)=1.5$ (100 years when $\mathrm{H}=100 \mathrm{~m}$ and $\alpha=1.58 \times 10^{-6} \mathrm{~m}^{2} / \mathrm{s}$ ). The comparison against the TRF - 'FLS - Uniform Temperature' shows that TRF-'FEM - EHCM' is slightly lower at short times, whereas the opposite behavior is observed when $\ln \left(t / t_{s}\right)>-1$.1. To illustrate this fact, at $\ln \left(t / t_{s}\right)=-4.5$, the TRF'FEM - EHCM' is 0.09 units (1.7\%) lower than the TRF 'FLS Uniform Temperature', whereas the TRF-'FEM - EHCM' is 0.09 units (0.6\%) higher than the TRF - 'FLS Uniform Temperature' at $\ln \left(\mathrm{t} / \mathrm{t}_{\mathrm{s}}\right)=1.5$. The TRF- 'FDM - Uniform Temperature' presents slightly higher values than TRF- 'FLS - Uniform Temperature' (0.06 and 0.15 units of difference when $\ln \left(t / t_{s}\right)$ is equal to -4.5 and 1.5 , respectively). These differences are attributed to the mesh utilized in the FDM. The TRF- 'FDM - Uniform Temperature' is 0.05 units higher than the TRF- 'FEM - EHCM' at $\ln \left(\mathrm{t} / \mathrm{t}_{\mathrm{s}}\right)=1.5$.

Fig. 2 illustrates the comparison of the (a) normalized heat flux and (b) temperature profiles at the borehole wall of the center and corner boreholes for a $2 \times 3$ bore field (geometrical aspect ratios as specified in Fig. 1) obtained from the HCM and EHCM models at one specific time $\left(\ln \left(\mathrm{t} / \mathrm{t}_{\mathrm{s}}\right)=0.1\right.$ which corresponds to 25 years when $\mathrm{H}=100 \mathrm{~m}$ and $\alpha=1.58 \times 10^{-6} \mathrm{~m}^{2} / \mathrm{s}$ ) when a total constant heat flow is injected into the bore field. To study the profile at the vicinity of the borehole wall, the heat flux and temperature profiles are obtained from the EHCM model at $1.01 \times r_{b}(0.0005 \mathrm{~m}$ away from the borehole wall) in order to avoid the transition between the fluid wall temperature and the borehole wall temperature [26]. 


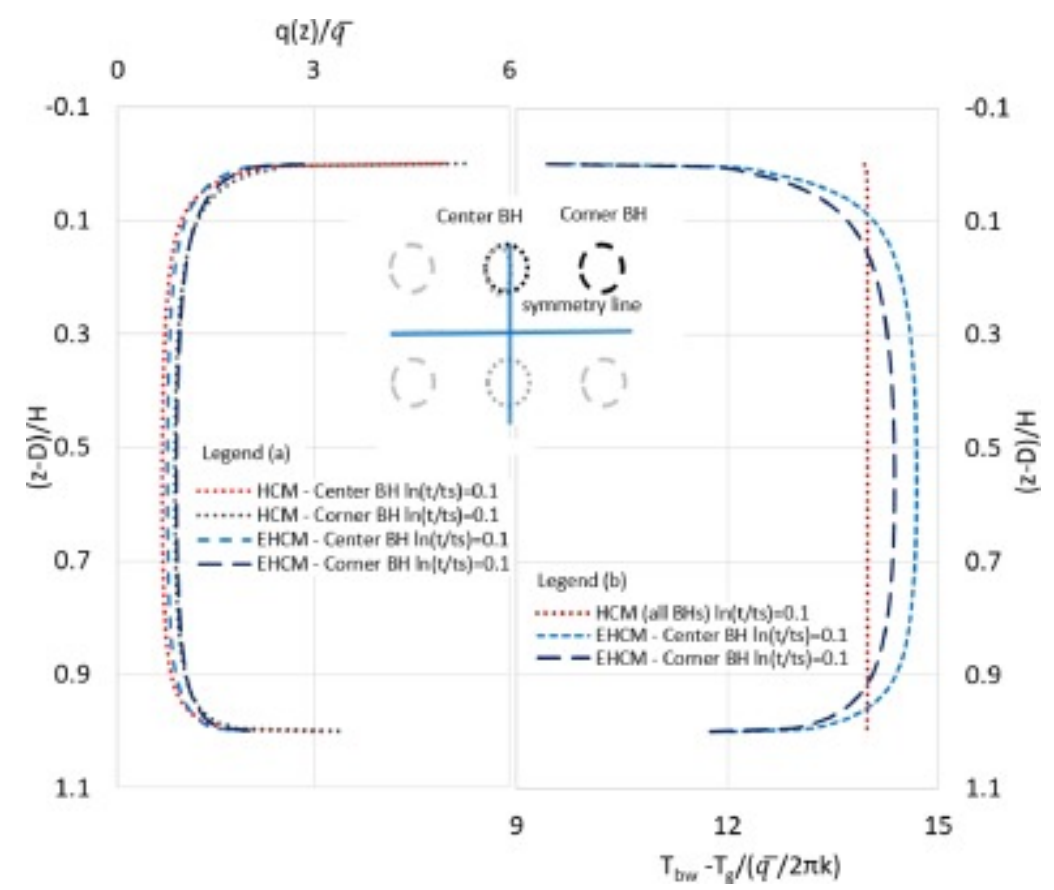

Fig. 2. Normalized heat flux and temperature along borehole length for a $2 \times 3$ bore field (geometrical aspect ratios as shown in Fig. $\left.1, \mathrm{k}=3.5 \mathrm{~W} /(\mathrm{m}-\mathrm{K}) ; \mathrm{R}_{\mathrm{b}}=0.1(\mathrm{~m}-\mathrm{K}) / \mathrm{W}\right)$ at $\ln \left(\mathrm{t} / \mathrm{t}_{\mathrm{s}}\right)=0.1(25$ years for $\mathrm{H}=100$ and $\alpha=1.58 \times 10^{-6} \mathrm{~m}^{2} / \mathrm{s}$ ) resulting from the HCM and the EHCM models.

In Fig. 2(b) it can be observed that the borehole wall temperature in each borehole is not the same, being higher in the center borehole. Average borehole wall temperatures in each borehole and the total average in all boreholes are shown in Fig. 6 . These results also illustrate that the thermal response of the ground at the borehole wall is not fully represented by the assumption of uniform borehole wall temperature with equal response in all boreholes. The difference of the average temperature along the borehole between the center borehole and the corner borehole is $0.35 \mathrm{~K}$ at steady state condition with $\mathrm{k}=3.5 \mathrm{~W} /(\mathrm{m}-\mathrm{K})$ and $\mathrm{R}_{\mathrm{b}}=0.1(\mathrm{~m}-\mathrm{K}) / \mathrm{W}$, see Fig. 6 . The heat flow distribution among and along the boreholes is illustrated in Fig. 2(b) and compared with previous results from the HCM model. The maximum heat flux at the corner borehole at $\ln \left(t / t_{s}\right)=0.1(25$ years when $\mathrm{H}=100 \mathrm{~m}$ and $\alpha=1.58 \times 10^{-6} \mathrm{~m}^{2} / \mathrm{s}$ ) resulting from the $\mathrm{HCM}$ model is $5.3 \mathrm{~W} / \mathrm{m}$, which is observed at the top edge. The maximum heat flux resulting from the EHCM model, which is also observed at the top edge, is $2.8 \mathrm{~W} / \mathrm{m}$ as shown in Fig. 2. Thus, the borehole thermal resistance has a substantial effect on the heat flux distribution at the borehole edges. In both the HCM and EHCM models, edge effects are greater at the top of the borehole, as a result of the smaller distance from the top borehole edge to the top surface.

Fig. 3 shows the effect with time of a constant heat injection in the (a) normalized heat flux and (b) temperature profiles along the borehole length of the center borehole in a $2 \times 3$ bore field at two specific times, $\ln \left(t / t_{s}\right)$ equal to -3.1 and 0.1 ( 1 and 25 years, respectively, when $H=100 \mathrm{~m}$ and $\left.\alpha=1.58 \times 10^{-6} \mathrm{~m}^{2} / \mathrm{s}\right)$. Edge effects are more prominent with time. A larger effect is observed at the top end of the borehole. Fig. 3 also shows the normalized profiles when the heat flux and temperature are calculated at 200 elements along the borehole depth. 


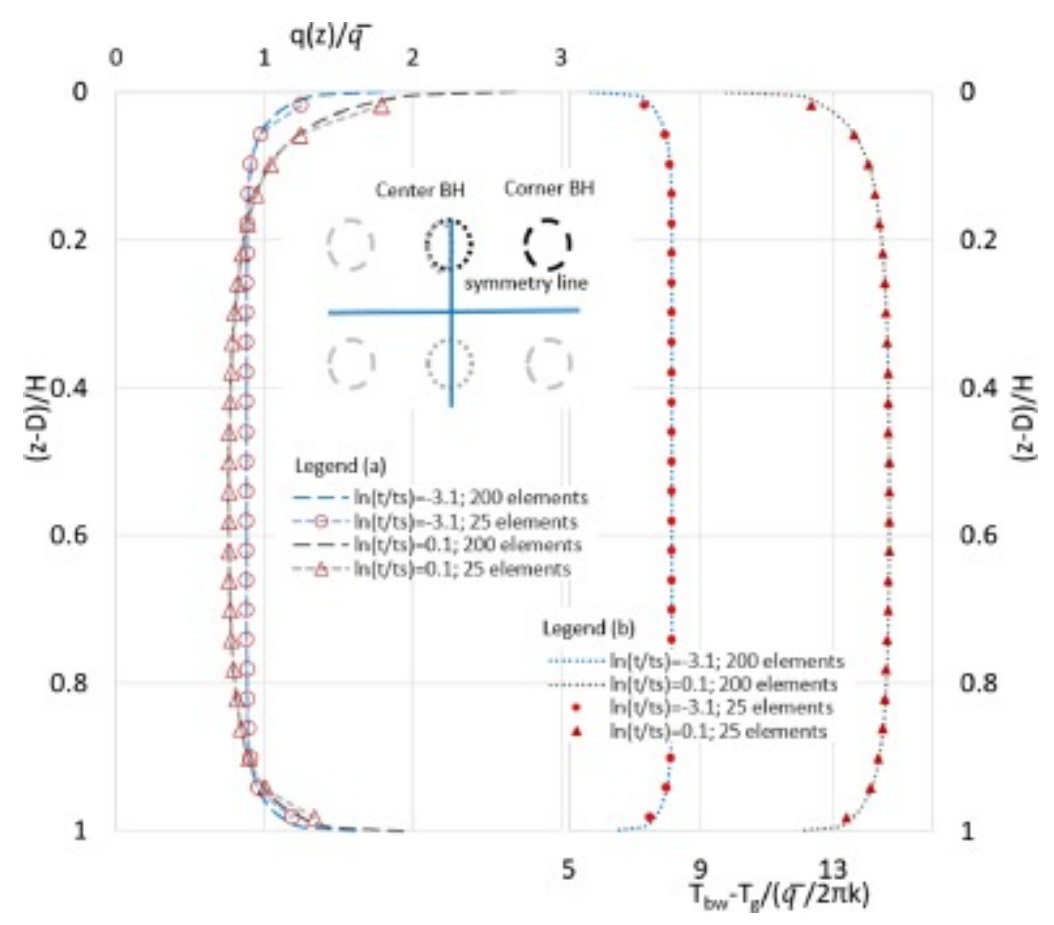

Fig. 3. Normalized heat flux and temperature at the center borehole in a $2 \times 3$ bore field (geometrical aspect ratios as shown in Fig. $1 ; \mathrm{k}=3.5 \mathrm{~W} /(\mathrm{m}-\mathrm{K}) ; \mathrm{Rb}=0.1(\mathrm{~m}-\mathrm{K}) / \mathrm{W})$ at $\ln \left(\mathrm{t} / \mathrm{t}_{\mathrm{s}}\right)=-3.1$ and $0.1(1$ and 25 years, respectively, for $\mathrm{H}=100$ and $\alpha=1.58 \times 10^{-6} \mathrm{~m}^{2} / \mathrm{s}$ ) resulting from the EHCM model with 200 and 25 discretized elements along the borehole length.

Fig. 3 also shows the profiles when the 200 elements are sorted out in 25 elements groups so that each group represents the average value of eight of the 200 elements and located at mid-height of that particular group. The profile with 25 elements group is of the same level of compression as used by Cimmino [4]. The edge effects are significantly reduced when the profiles are discretized in 25 element groups, as shown in Fig. 3.

Fig. 4 illustrates the normalized heat flow per borehole within a $2 \times 3$ bore field with geometrical aspect ratios as described in Fig. 1 resulting from the EHCM model when a total constant heat flow injection is imposed in the bore field. The results here are compared with the results from the HCM model previously reported in Monzó et al. [23]. Improvements in the meshing strategy have overcome the HCM model limitations to compute the heat flow per borehole, as illustrated by the wiggles, for periods of $\ln \left(\mathrm{t} / \mathrm{t}_{\mathrm{s}}\right)<-1.8$ (around 3.5 years for $\mathrm{H}=100$ and $\alpha=1.58 \times 10^{-6} \mathrm{~m}^{2} / \mathrm{s}$ ), as observed in Fig. 4. 


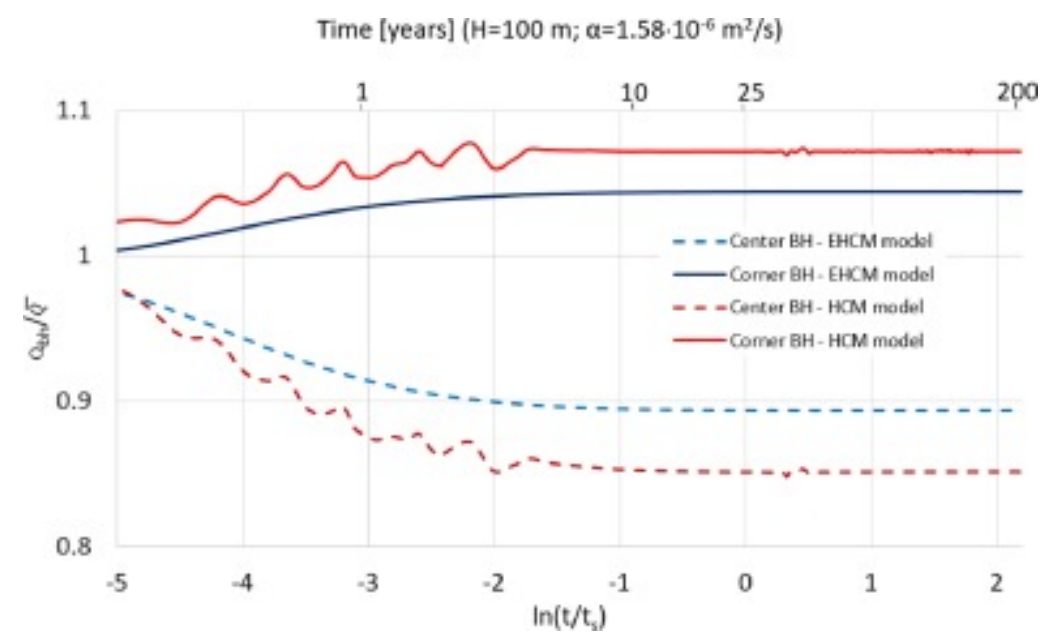

Fig. 4. Normalized heat flow per borehole in a $2 \times 3$ bore field (geometrical aspect ratios as shown in Fig. $3 ; \mathrm{k}=3.5 \mathrm{~W} /(\mathrm{m}-\mathrm{K}) ; \mathrm{Rb}=0.1(\mathrm{~m}-\mathrm{K}) / \mathrm{W})$ resulting from the $\mathrm{EHCM}$ model and compared to previous results from the HCM model.

In Fig. 4, the comparison of the results from the EHCM model against the HCM model also shows that the heat flow among the boreholes tends to be more evenly distributed when the GHE thermal resistance is considered. For $\ln \left(t / t_{s}\right)>-2$, the normalized heat flow in the corner borehole has changed from 1.07 to $1.04(-3 \%)$, while the share of the center borehole has changed from 0.85 to 0.89 (4\%). At short times the distribution of the heat flow per borehole is very similar in all boreholes. Differences in the heat flow distribution show an increasing tendency until a period around $\ln \left(t / t_{s}\right)=-2$, at which the heat flow distribution per borehole is kept virtually constant during the remaining period. The error of the EHCM model for the total heat flow calculation after simulation and compared to the input value is around $0.6 \%$ for the time period at all instances.

The small difference between the TRFs resulting from the EHCM model with a given GHE thermal resistance and the g-function approaches, reflect the small influence of the borehole edges (top and bottom) in comparison to the total borehole length in the heat transfer rate. Although there are no significant differences on the TRFs resulting from the EHCM model and from HCM model, the improvements applied to the EHCM model are able to reproduce the effect of the GHE thermal resistance on the heat flux and temperature profiles along the borehole wall.

An analysis of the GHE thermal resistance is performed to evaluate the influence of this parameter on the heat flow distribution among the boreholes and on the temperature and heat flux distribution at the borehole walls. Fig. 5 shows the (a) normalized heat flux and (b) temperature profiles of the center and corner boreholes at steady state when the GHE thermal resistance is varied from 0.001 to 0.1 and $1(\mathrm{~m}-\mathrm{K}) / \mathrm{W}$ when heat is injected to the ground. It can be observed that for $R_{b}$ equal to $0.001(\mathrm{~m}-\mathrm{K}) / \mathrm{W}$ the normalized heat flux presents the largest heat flux at the borehole edges, while temperature profiles are almost uniform and the same in all the boreholes. This result resembles the one from the HCM model, with no GHE thermal resistance. When the GHE thermal resistance is increased up to $1(\mathrm{~m}-\mathrm{K}) / \mathrm{W}$ the normalized heat flux along the borehole length remains almost uniform along the borehole depth in all the boreholes, 
while normalized temperature profiles present the largest edge effects and a large difference can be observed on the temperature profiles as compared to the other two analyzed cases ( $R_{b}$ equal to 0.001 and $\left.0.1(\mathrm{~m}-\mathrm{K}) / \mathrm{W}\right)$ and with different response in each borehole.

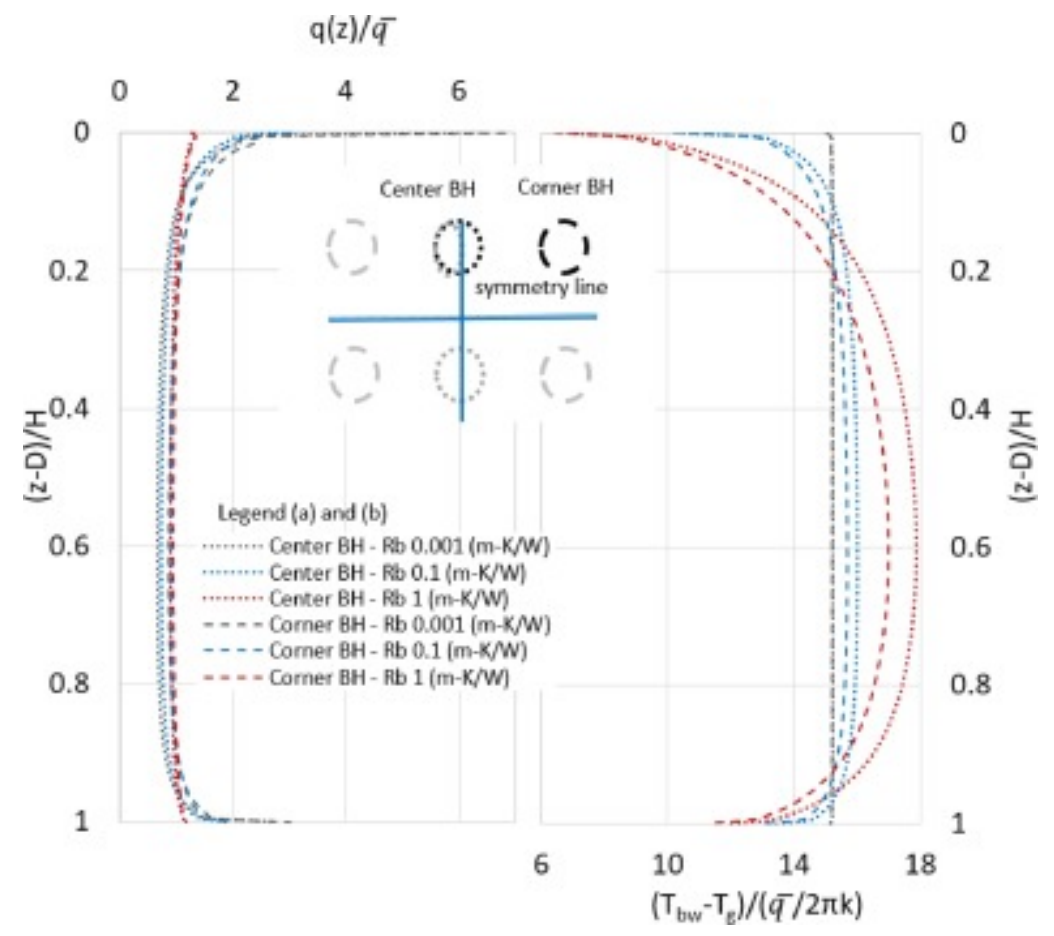

Fig. 5. Normalized (a) heat flux and (b) temperature profiles of the representative boreholes in a $2 \times 3$ bore field at steady state for different values of GHE thermal resistance $\left(R_{b}\right)$ and $k=3.5 \mathrm{~W}(/ \mathrm{m}-\mathrm{K})$.

Fig. 6 shows the influence of the GHE thermal resistance on the (a) normalized heat flow distribution and (b) average borehole wall temperature per borehole when heat is injected to the ground. 


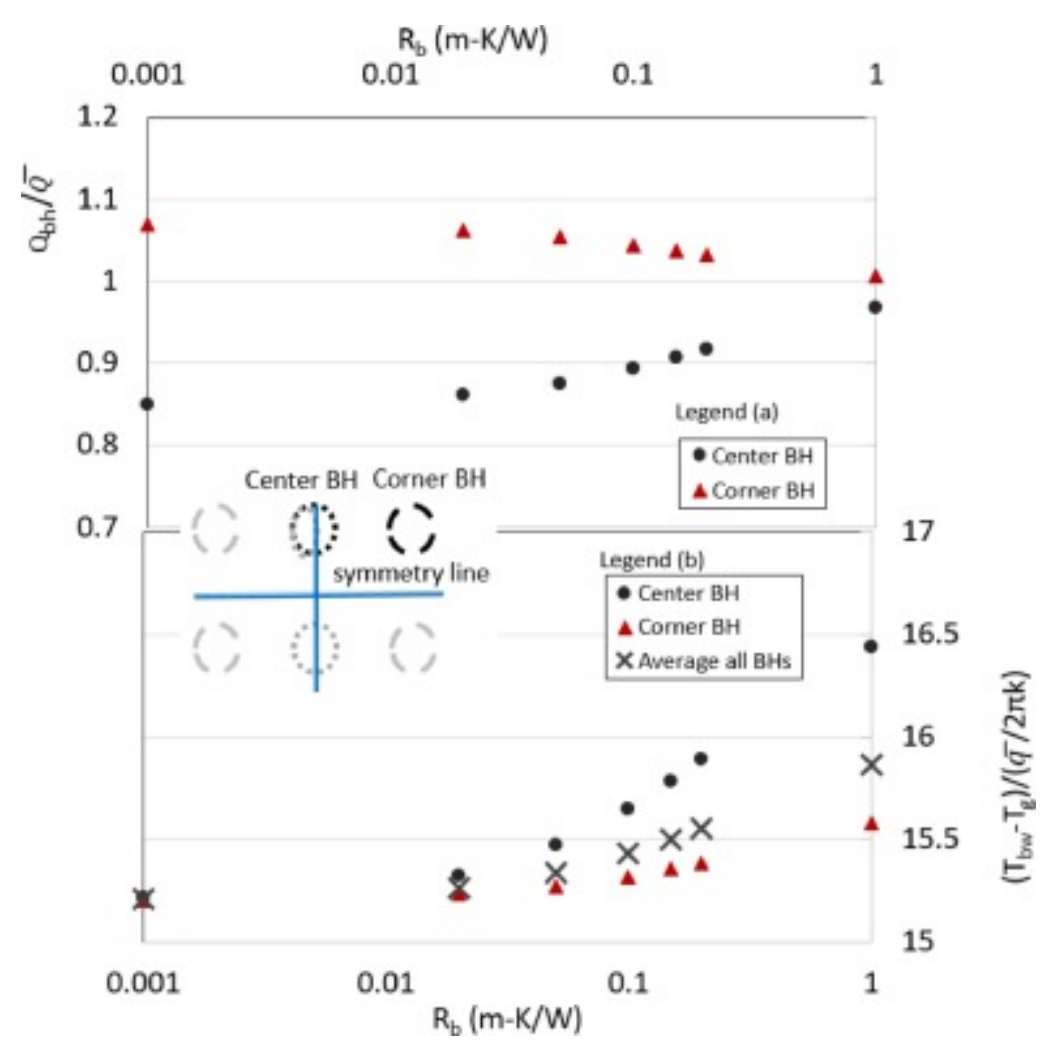

Fig. 6. Normalized (a) heat flow per borehole and (b) borehole wall temperature in a $2 \times 3$ bore field at steady state for different values of the GHE thermal resistance $\left(R_{b}\right)$ and $k=3.5 \mathrm{~W} /(\mathrm{m}-\mathrm{K})$.

As in accordance with Fig. 5 ; Fig. 6(a) shows that the heat flow tends to be more equally distributed among the boreholes as the GHE thermal resistance increases, being almost equal to 1 when $R_{b}=1(m-K) / W$. For very large values of $R_{b}$, the boreholes act as cylindrical heat sources with uniform heat flux. If the GHE thermal resistance decreases, the differences in the average borehole wall temperature among the borehole decrease, being minor for $R_{b}=0.001(m-K) / W$, which is in accordance with the observations in Fig. 5(b). The errors of the total heat flow calculations presented in Figs. 5 and 6 as compared to the input value given in the model range around $\pm 0.4 \%$ when $R_{b}$ varies from 0.02 and $0.2(\mathrm{~m}-\mathrm{K}) / \mathrm{W}$, respectively, with and error $0.1 \%$ for $\mathrm{R}_{\mathrm{b}}$ equal to 0.001 (m$\mathrm{K}) / \mathrm{W}$. The error increases up to $-0.8 \%$ and $2.6 \%$ for $R_{b}$ equal to 0.001 and $1(\mathrm{~m}-\mathrm{K}) / \mathrm{W}$, respectively.

\subsection{TRFs for a $4 \times 4$ bore field}

The work presented in Cimmino [4] is used as reference and the $4 \times 4$ bore field for the geometrical aspect ratios reported in this work is reproduced in the present paper using the EHCM model when the GHE thermal resistance, $R_{b}=0.1(m-K) / W$ and the soil thermal conductivity, $\mathrm{k}=3.5 \mathrm{~W} /(\mathrm{m}-\mathrm{K})$.

Fig. 7 shows the TRFs for a $4 \times 4$ bore field (geometrical aspect ratios as specified in Fig. 7) obtained from the EHCM model along with TRFs from the aforementioned reference solutions:' FDM - Uniform Temperature', 'FLS - Uniform Temperature' and the solution from the HCM model when a total constant heat injection is imposed to the bore 
field. Fig. 7 also contains the TRF resulting from the model proposed in Cimmino [4] with a non-dimensional thermal conductance equal to 0.300 , a non-dimensional fluid flow rate 0.9425 and a non-dimensional borehole thermal resistance of 2.19 with $\mathrm{k}=3.5 \mathrm{~W} /(\mathrm{m}-\mathrm{K})$, tagged as Cimmino [4].

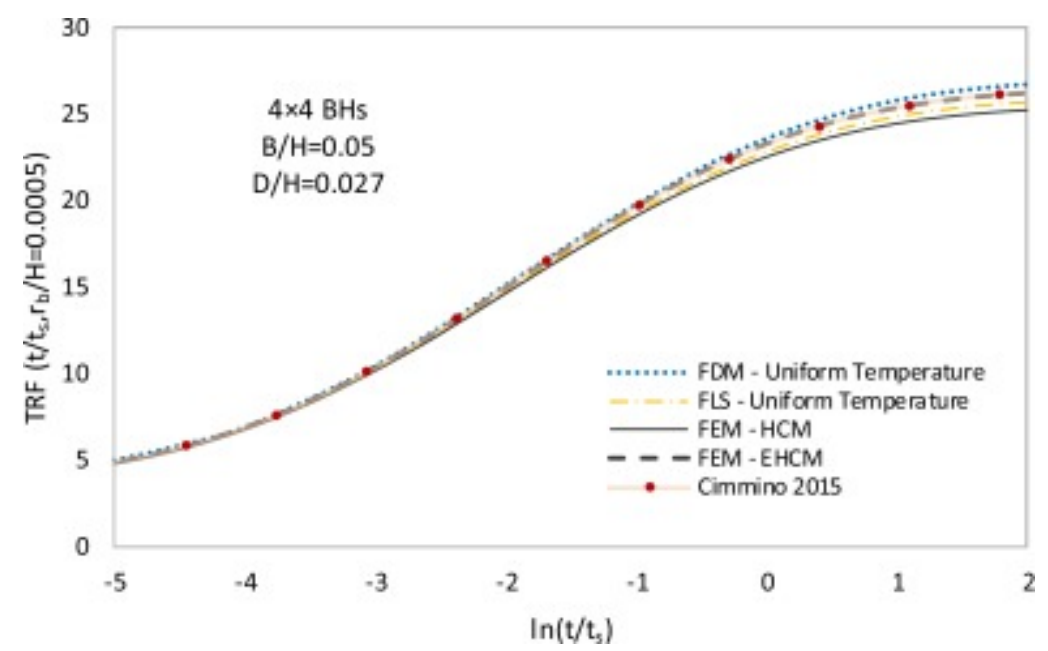

Fig. 7. TRFs for a $4 \times 4$ bore field for given geometrical aspect ratios $\left(k=3.5 \mathrm{~W} /(\mathrm{m}-\mathrm{K}) ; \mathrm{R}_{b}=0.1(\mathrm{~m}-\mathrm{K}) / \mathrm{W}\right.$ in the EHCM model).

The comparison of the TRFs shows that at short times, differences between all solutions are barely appreciable. For long times, when $\ln \left(t / t_{s}\right)>0$, differences between the TRFs start to be distinguishable. In general the TRF-'FEM - HCM' tends to underestimate the response as compared to the TRF-'FEM - EHCM'. For instance, when $\ln \left(t / t_{s}\right)=-4.5$ (around 200 days for $\mathrm{H}=150$ and $\alpha=1.58 \times 10^{-6} \mathrm{~m}^{2} / \mathrm{s}$ ) TRF-'FEM - HCM' underestimates the response by 0.03 units $(0.6 \%)$ and by $0.89(3.4 \%)$ units when $\ln \left(\mathrm{t} / \mathrm{t}_{\mathrm{s}}\right)=1.5$ (around 224 years for $\mathrm{H}=150$ and $\alpha=1.58 \times 10^{-6} \mathrm{~m}^{2} / \mathrm{s}$ ). The TRF resulting from the HCM model deviates from TRF - 'FLS Uniform Temperature' $-1.5 \%$ at $\ln \left(\mathrm{t} / \mathrm{t}_{\mathrm{s}}\right)=1.5$. The comparison of the TRF-'FEM - EHCM' and TRF- 'FLS - Uniform Temperature' shows that the EHCM model deviates -0.01 units $(-0.3 \%)$ as compared to TRF- 'FLS - Uniform Temperature' and $0.5(2 \%)$ at $\ln \left(\mathrm{t} / \mathrm{t}_{\mathrm{s}}\right)$ equal to -4.5 and 1.5 , respectively. The analysis of the comparison of TRF - 'FEM - EHCM' against TRF - 'Cimmino [4]' shows that at a time equal to $\ln \left(t / t_{s}\right)=-4.5$, the EHCM model results in slighter lower values with 0.02 units difference (0.3\%). At $\ln \left(\mathrm{t} / \mathrm{t}_{\mathrm{s}}\right)=1.5$, the TRF - ' $\mathrm{FEM}-\mathrm{EHCM}^{\prime}$ is 0.03 units $(0.1 \%)$ higher than the TRF - 'FLS - Cimmino [4]'. The deviation observed between the TRF resulting from the 'FLSUniform Temperature' and the 'EHCM' model at steady state are of the same magnitude $(2 \%)$ as compared to the deviation observed in [4] in an equivalent comparison. For $\ln \left(\mathrm{t} / \mathrm{t}_{\mathrm{s}}\right)=-2$, the TRF - 'FDM - Uniform Temperature' starts to deviate as compared to its equivalent solution (TRF- 'FLS - Uniform Temperature'). It overestimates the temperature which increases with time. At $\ln \left(t / t_{s}\right)=-4.5$, TRF - 'FDM - Uniform Temperature' overestimates by 0.12 units the bore field temperature response as compared to TRF- 'FLS - Uniform Temperature', while a difference of 1.03 units is observed when these two solutions are compared at $\ln \left(t / t_{s}\right)=1.5$. The differences observed when comparing the TRF - 'FDM - Uniform Temperature' against approaches based on a uniform borehole wall temperature are partly attributed to the aspect ratio 
$\mathrm{D} / \mathrm{H}$, which is disregarded in the finite difference solution. The TRF - 'FDM - Uniform Temperature' as compared to the TRF - 'FEM - EHCM' overestimates the response by 0.1 and 0.5 units when $\ln \left(t / t_{s}\right)=-4.5$ and 1.5 , respectively, which results in $2 \%$ deviation for both examined instances.

Fig. 8 shows the normalized (a) heat flux and (b) temperature profiles at the borehole wall (at a distance $1.01 \times r_{b}$ ) at steady state for each representative borehole within a $4 \times 4$ bore field (geometrical aspect ratios as specified in Fig. 7) for a $R_{b}=0.1(m-K) / W$ with a given heat flow injection. The heat flux and temperature profiles are represented by both 200 points and 25 element groups along the borehole length. For 200 elements discretization, higher heat flux and temperature values are observed at boreholes edges, being larger at the top edge. As above, the results from the 200 element discretization is sorted out in 25 element groups, as explained above. The 25 element groups analysis reduces significantly the maximum heat flux and temperature values, resembling the results presented in [4]. It can also be observed that the temperature at the borehole wall is different in each borehole, due to the thermally resistive layer. The temperature difference between the center borehole and the corner borehole is $1.3 \mathrm{~K}$ at steady state. The difference between temperatures inside the inner and the corner boreholes increases with the number of boreholes, at least for packed bore fields.

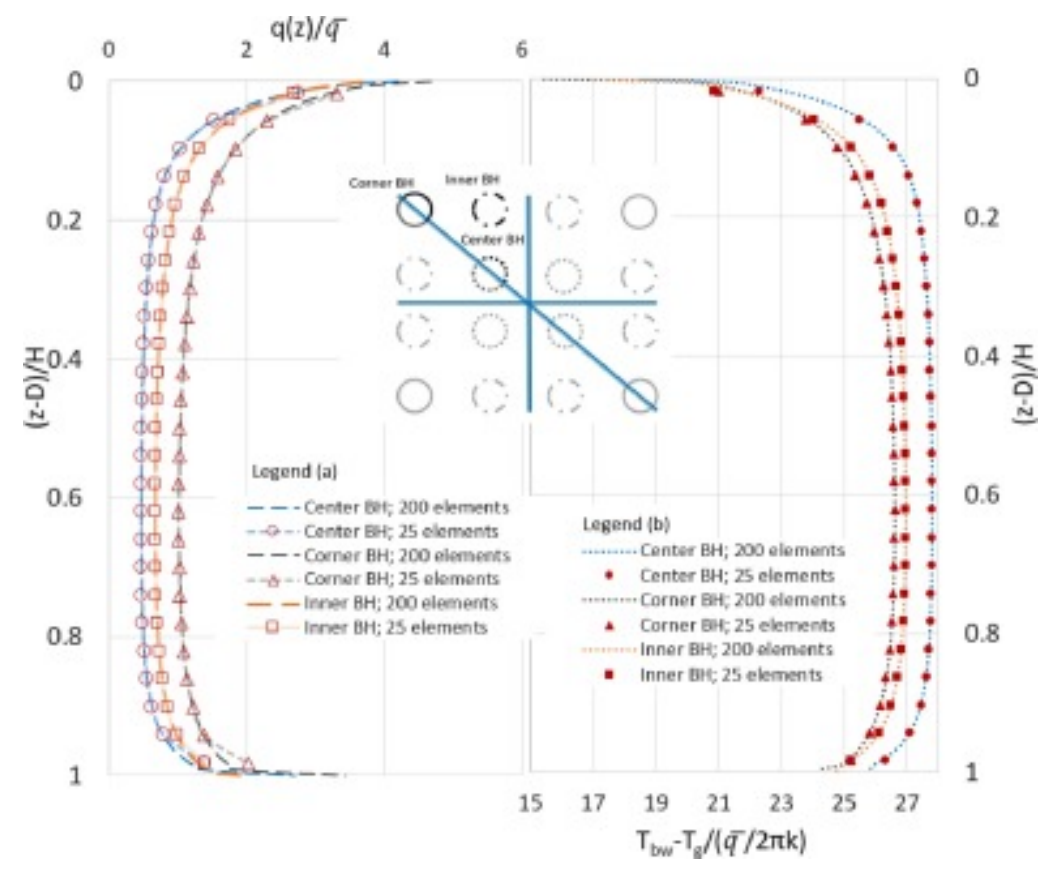

Fig. 8. Normalized heat flux and temperature of representative boreholes in a $4 \times 4$ bore field (geometrical aspect ratios as shown in Fig. 7) and $R_{b}=0.1(\mathrm{~m}-\mathrm{K}) / \mathrm{W}$ and $\mathrm{k}=3.5 \mathrm{~W} /(\mathrm{m}-\mathrm{K})$ at steady state resulting from the EHCM model with 200 and 25 discretized elements along the borehole length.

With regard to the GHE thermal resistance $\left(R_{b}\right)$, a sensitivity analysis is also performed for the given $4 \times 4$ bore field in Fig. 7. The GHE thermal resistance is varied between 0.001 and $1(\mathrm{~m}-\mathrm{K}) / \mathrm{W}$. The results are shown in Figs. 9 and 10. Fig. 9 shows the (a) normalized heat flux and (b) temperature profiles at representative boreholes at steady state when heat is injected to the ground. Fig. 10 shows (a) the normalized total heat flow per representative borehole and (b) the average temperature along the borehole 
length at steady state against $R_{b}$ with heat injection. As $R_{b}$ decreases, the heat flow distribution among the boreholes is more unequal, so that the corner boreholes exchange a larger amount of heat than the boreholes in the central part of the bore field. The temperature responses at walls in each borehole, with decreasing $R_{b}$, result in very similar profiles, as shown in Fig. 9(b). This behavior can also be observed in Fig. 10(b) as the differences in their average borehole wall temperature between the boreholes are very small. The case of $R_{b}=0.001(\mathrm{~m}-\mathrm{K}) / \mathrm{W}$ resembles the models with uniform borehole wall temperature condition. On the other hand, the heat flow distribution among the boreholes tends to be equal when $R_{b}$ increases, behaving as cylindrical sources with constant heat flux along the borehole length when $R_{b}=1$ (m$\mathrm{K}) / \mathrm{W}$. The temperature response for large values of $R_{b}$ shows that differences are larger among the boreholes and at the edges, see Figs. $9(\mathrm{~b})$ and $10(\mathrm{~b})$. The error of the results presented in Figs. 9 and 10 varies between $-0.5 \%$ and $0.4 \%$ for $R_{b}$ varying between 0.05 and $0.15(\mathrm{~m}-\mathrm{K}) / \mathrm{W}$, respectively; with $0.1 \%$ error for $\mathrm{R}_{\mathrm{b}}$ equal to $0.1(\mathrm{~m}-\mathrm{K}) / \mathrm{W}$, while the deviation increases up to around 3.5\% for both extreme values of $R_{b}(0.001$ and 1 (mK)/W).

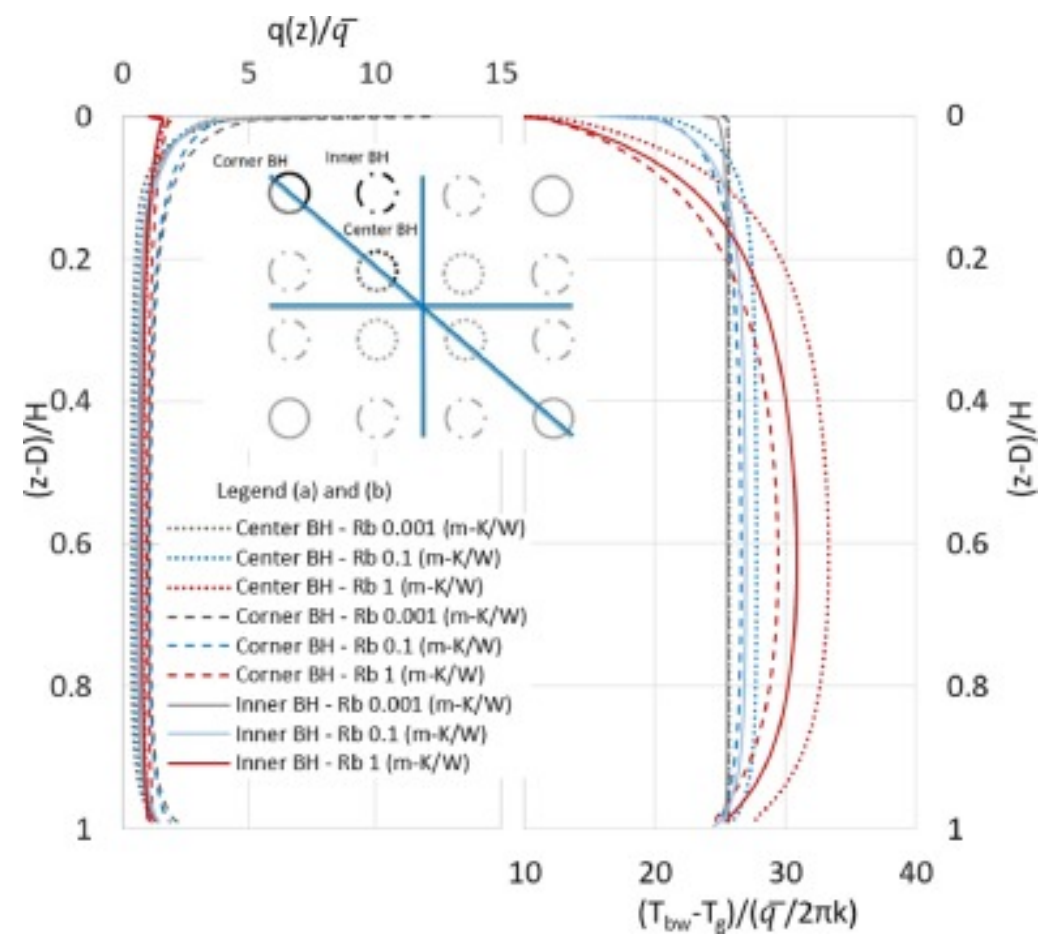

Fig. 9. Normalized (a) heat flux and (b) temperature profiles of representative boreholes in a $4 \times 4$ bore field at steady state for different GHE thermal resistances and $k=3.5 \mathrm{~W} /(\mathrm{m}-\mathrm{K})$. 


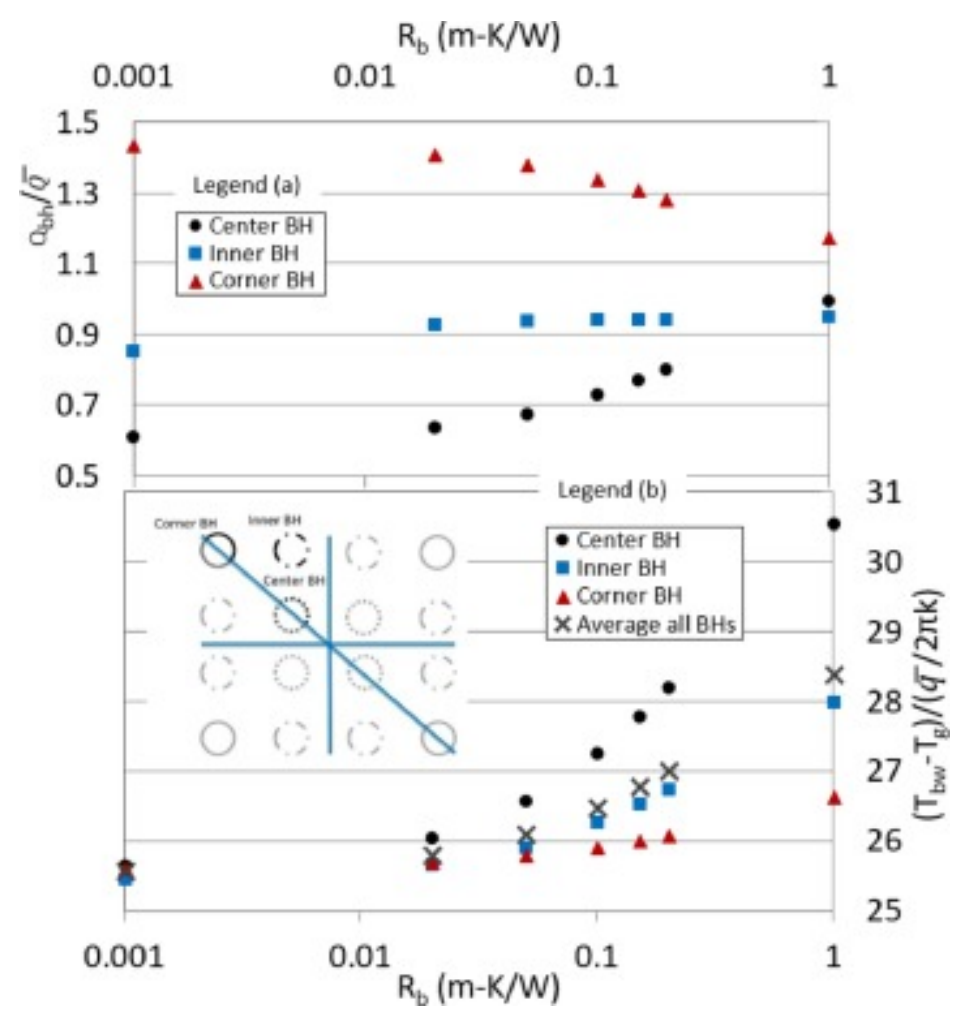

Fig. 10. Normalized (a) heat flow per borehole and (b) borehole wall temperature in a $4 \times 4$ bore field at steady state for different GHE thermal resistance and $k=3.5 \mathrm{~W} /(\mathrm{m}-\mathrm{K})$.

\section{Illustration of daily fluid temperature predictions and comparison with measured data}

Once the EHCM model has been validated for the generation of the TRFs, it is employed to simulate daily fluid temperatures of two monitored GCHP installations.

\subsection{Description of the monitored GCHP installations}

The first GCHP installation under study supplies space heating and domestic hot water to an elementary school located in the northwest of Spain, Galicia. This installation comprises a heat pump, with a nominal capacity of $52 \mathrm{~kW}$. On the building side, the heat pump is connected to a radiant floor heating system for SPH and to a thermal buffer tank of 1500 I that serves as an instantaneous DHW supply. The outdoor circuit coupled to the heat pump consists of $5 \mathrm{GHEs}$ connected in parallel. The borehole length is $120 \mathrm{~m}$ each with an inactive upper depth of $2 \mathrm{~m}$. The borehole diameter is $140 \mathrm{~mm}$ with a double-U tube HDPE SDR $1132 \times 2.9 \mathrm{~mm}$. The borehole is grouted with a mixture of sand, concrete and bentonite materials. Further details about this installation are described in Iglesias et al. [15] and Puttige [26]. The operation of the system has been monitored since the beginning of the operation in February 2010 until January 2014. Before the system started operating some heat injection tests were performed during January 2010. Measurements are missing from that period.

The second monitored GCHP installation studied in this paper was built in the framework of a European FP5 project called, GeoCool, at the Universitat Politecnica de València in 
Valencia, on the east coast of Spain. The system has been in operation since February 2005 for the air conditioning of a set of offices at the Department of Applied Thermodynamics. A more detailed description of this GCHP system has been presented in previous publications by Montagud et al. [21] and Corberán et al. [9]. The bore field consists of 6 vertical GHEs, arranged in a $2 \times 3$ rectangular grid, with a borehole-toborehole spacing of $3 \mathrm{~m}$. Each borehole is $51 \mathrm{~m}$ deep with $1 \mathrm{~m}$ of header depth and has a diameter of $150 \mathrm{~mm}$. The groundwater level is about $3.5 \mathrm{~m}$. The boreholes contain a single HDPE U-tube $32 \times 3.3 \mathrm{~mm}$ with a $70 \mathrm{~mm}$ separation between the upward and downward shanks. The space between the U-pipe and the borehole wall is filled in each borehole with a particular grouting material such as sand of different granularity [13]. The top layer of the borehole is filled with bentonite to prevent migration of pollutants into the borehole. The GCHP installation has been monitored since the beginning of operation up to now. The thermal response of this bore field was previously studied with the HCM model for about six years of operation, as reported in Monzó et al. [23]. A summary of source data for the two monitored GCHP is shown in Table 1. The former installation is referred to as 'Facility 1 ', while 'Facility 2 ' refers to the latter installation.

Table 1. Summary of source data of the monitored GCHP installations.

\begin{tabular}{|c|c|c|c|}
\hline \multicolumn{2}{|c|}{ Reference } & \multirow[b]{2}{*}{ Facility 1} & \multirow[b]{2}{*}{ Facility 2} \\
\hline & & & \\
\hline \multicolumn{2}{|c|}{ Location } & Galicia, Spain & Valencia, Spain \\
\hline \multicolumn{2}{|c|}{ Monitored period } & $\begin{array}{l}\text { February } 2010 \text { - January } \\
2014\end{array}$ & February 2005 - present \\
\hline \multicolumn{2}{|c|}{ Building Demand } & $\begin{array}{l}\text { Space heating and } \\
\text { domestic hot water }\end{array}$ & $\begin{array}{l}\text { Space cooling and } \\
\text { heating }\end{array}$ \\
\hline \multirow[t]{4}{*}{$\begin{array}{l}\text { Bore } \\
\text { field }\end{array}$} & Bore field layout & $2 \times 3$ BHs U-configuration & $\begin{array}{l}2 \times 3 \text { BHs Rectangular } \\
\text { configuration }\end{array}$ \\
\hline & $\mathrm{D} / \mathrm{H}$ & 0.017 & 0.074 \\
\hline & $r_{b} / H$ & 0.0006 & 0.0016 \\
\hline & $\mathrm{B} / \mathrm{H}$ & 0.068 & 0.063 \\
\hline \multirow[t]{3}{*}{$\begin{array}{l}\text { Soil } \\
\text { data }\end{array}$} & $\begin{array}{l}\text { Undisturbed } \quad \text { ground } \\
\text { temperature }\left(T_{g}\right)\end{array}$ & $16.5^{\circ} \mathrm{C}$ & $18.5^{\circ} \mathrm{C}$ \\
\hline & $\begin{array}{ll}\text { Ground } & \text { thermal } \\
\text { conductivity }(k) & \end{array}$ & $2.9 \mathrm{~W} /(\mathrm{m}-\mathrm{K})$ & $1.6 \mathrm{~W} /(\mathrm{m}-\mathrm{K})$ \\
\hline & $\begin{array}{l}\text { Volumetric heat capacity } \\
\text { (C) }\end{array}$ & $2.4 \mathrm{MJ} /\left(\mathrm{m}^{3}-\mathrm{K}\right)$ & $2.2 \mathrm{MJ} /\left(\mathrm{m}^{3}-\mathrm{K}\right)$ \\
\hline \multicolumn{2}{|c|}{$\begin{array}{l}\text { Effective GHE thermal resistance } \\
\left(R_{b}{ }^{*}\right)\end{array}$} & $0.087(\mathrm{~m}-\mathrm{K}) / \mathrm{W}$ & $0.118(\mathrm{~m}-\mathrm{K}) / \mathrm{W}$ \\
\hline
\end{tabular}




\subsection{Modeling the thermal response of the bore fields with the EHCM model}

The procedure to simulate the thermal response of the bore fields of these two monitored GCHP installations using the EHCM model is similar to the procedure explained above with use of the HCM and the TRL. Similarly, the undisturbed ground temperature is defined at the outer boundary of the surrounding ground.

The bore fields are built up according to their corresponding geometrical aspect ratios, as listed in Table 1. In both facilities, taking advantage of the bore field symmetry, computing domain is reduced via an adiabatic wall in the plane of symmetry. The volume of the surrounding ground is built so that it is large enough to ensure that the steady state asymptote is reached when TRF is generated. The surrounding ground of the bore field in 'Facility 1 ' is represented by a cylinder of radius $150 \mathrm{~m}$ and depth $240 \mathrm{~m}$. The surrounding volume of the bore field in 'Facility 2', consists of about $200 \times 249 \mathrm{~m}$ in the horizontal plane with $200 \mathrm{~m}$ depth and in the inactive upper part, similar to its previous version in Monzó et al. [23]. The thermal properties of the ground are defined according to the values at the site, as listed in Table 1 . The initial temperature is set equal to the undisturbed temperature measured at the site. The value of the thermal conductivity of the TRL is defined so that the thermal resistance of the GHE is represented according to their corresponding measured values in Table 1 and as expressed in Eq. (2). The total heat flow defined as a heat rate across the boundaries on the HCM bar, either constant for the TRFs (Section 5.3) or variable according to measurements (Section 5.4).

A similar strategy as explained in Section 3 is applied to build the mesh for these two monitored bore fields. The mesh comprises around 200,000 elements in total in either bore field. The simulations of these two monitored bore fields are performed on a computer with an Intel Core i7 $2.8 \mathrm{GHz}$ processor and 8GB RAM. The prediction of daily fluid temperatures in 'Facility 1 ' over 4 years of operation requires $5.5 \mathrm{~h}$, whereas the computing time is around $12 \mathrm{~h}$ for 11 years in 'Facility 2 '.

Firstly, the EHCM model is used to generate the TRFs according to the geometrical aspect ratios of the bore fields and the GHE thermal resistances in Table 1. Once models are validated for TRF solutions, they are used to simulate fluid temperatures for measured variable loads. A similar procedure is applied in both cases, which is explained below.

At any given time, $t$, the measured loads are utilized to simulate average borehole wall temperatures $\left(T_{b w}\right)$ in the bore field. The fluid temperature $\left(T_{f}\right)$ is obtained from the relation between the fluid and the average borehole wall temperature, using the traditional effective GHE thermal resistance $\left(R_{b}{ }^{*}\right)$ approach, and the average heat transfer rate per unit length $(\bar{q})$, as expressed in Eq. 3. As mentioned above, the measured loads are aggregated in daily steps and the analysis is carried out for daily average values, with $t$ representing daily steps in Eq. (3):

equation(3) 
$T_{f}(t)=T_{b w}(t)+\bar{q}(t) \cdot R_{b}{ }^{*}$

The calculation of the average boreholes walls temperature in the bore field was performed by two different procedures in earlier studies presented in [26]. The first procedure consists of giving as an input in the finite element model the total measured variable load exchanged in the bore field. Next, the average boreholes walls temperature in the bore field is obtained from the average of the walls temperatures in all the boreholes at any given time. The second procedure is to calculate the average boreholes walls temperature by temporal superposition of the total measured variable load over the TRFs. The study about the comparison of these two procedures was reported in Puttige [26]. Although there were not significant differences between the results from both procedures, slightly closer agreement with the measured data was observed for the simulated values resulting from the procedure with direct input of measured variable loads [26]. In this work the first procedure is used to simulate the fluid temperatures responses for the two cases studied, as presented in Figs. 13 and 14, and for all the different approaches: (1) FEM CQ (2) FEM HCM and (3) FEM - EHCM.

\subsection{TRFs for the bore fields of the monitored GCHP installations}

Figs. 11 and 12 show the TRF resulting from the EHCM model, tagged as EHCM, and the TRF from reference solutions. The TRFs from reference solutions are tagged as in Section 4. 'FDM Uniform Temperature' is referred to the solution from the SBM with uniform temperature at the borehole wall, 'FLS Uniform Temperature' is the solution from the analytical solution with uniform borehole wall temperature and ' $\mathrm{FEM} \mathrm{HCM}$ ' is the response from the HCM model. Figs. 11 and 12 also include the TRF when a constant heat flux boundary condition is defined at the borehole wall, which is obtained from the pure FLS approach and the FEM solution in Monzó et al. [22]. The TRFs resulting from these solutions are tagged as 'FLS Constant Heat flux' and 'FEM Constant Heat flux', respectively.

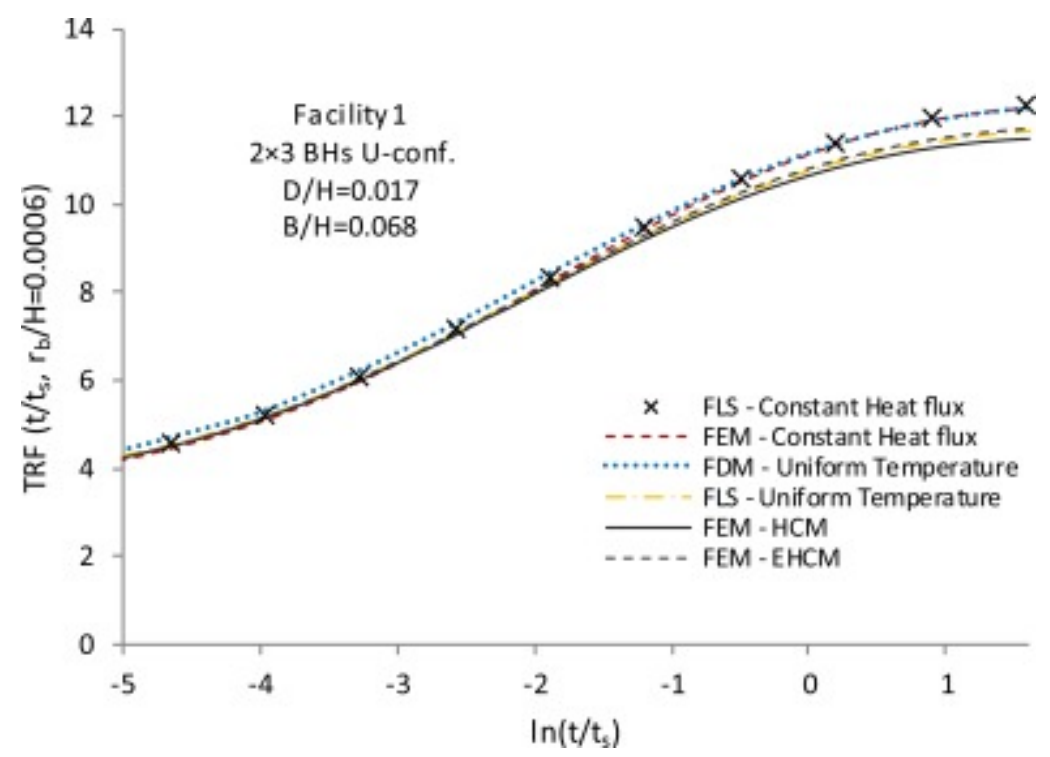

Fig. 11. TRFs for the bore field of 'Facility 1'. 


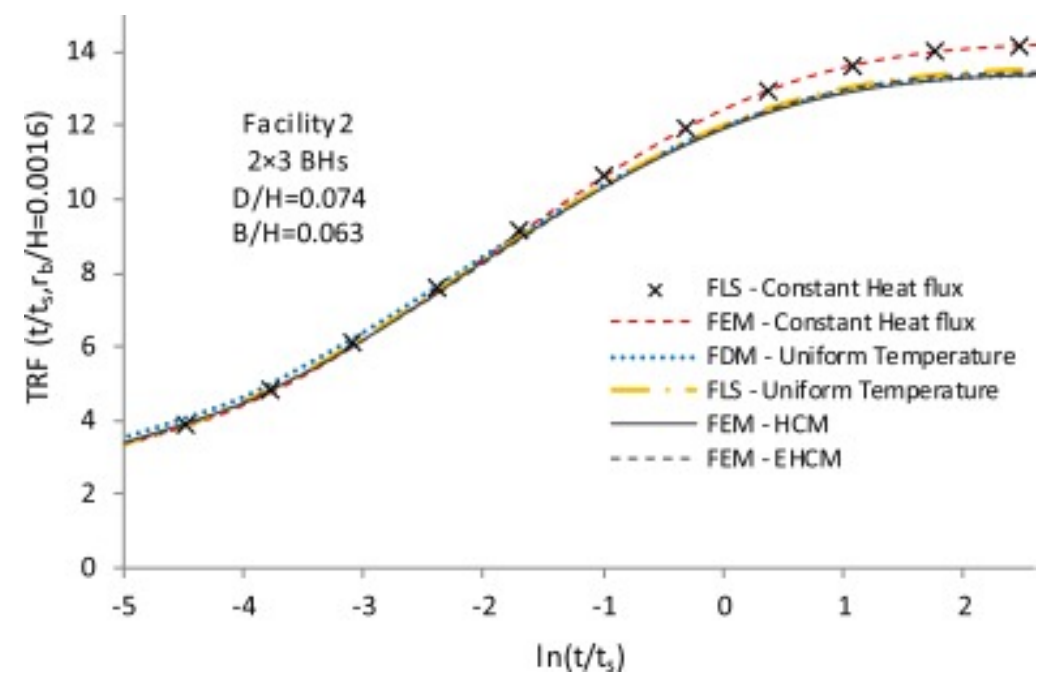

Fig. 12. TRFs for the bore field of 'Facility 2'.

Table 2 summarizes the analysis of the comparison of the TRF resulting from EHCM model against reference solutions. It also shows the deviation in terms of temperature at given times when a heat flow per unit length of $20 \mathrm{~W} / \mathrm{m}$ is assumed. In general, the TRF- 'FEM EHCM' present slightly higher values than the TRF resulting from the previous HCM model. In the study of both 'Facility 1 ' and 'Facility 2', deviations of the TRF- 'FEM EHCM' against the TRF- 'FEM HCM' are of the same magnitude.

Table 2. Summary of deviations of the TRF resulting from EHCM model against reference solutions.

\begin{tabular}{|c|c|c|c|c|c|c|c|}
\hline $\begin{array}{l}\text { Deviations of } \\
\text { TRFs - reference } \\
\text { solutions } \\
\text { against TRF - } \\
\text { FEM-EHCM }\end{array}$ & & \multicolumn{2}{|c|}{ FEM - HCM } & \multicolumn{2}{|c|}{$\begin{array}{l}\text { FLS - Uniform } \\
\text { Temperature }\end{array}$} & \multicolumn{2}{|c|}{$\begin{array}{l}\text { FEM - Constant } \\
\text { Heat Flux }\end{array}$} \\
\hline \multirow{2}{*}{\multicolumn{2}{|c|}{$\ln \left(t / t_{s}\right)$}} & & & & & & \\
\hline & & -4.5 & 1.5 & -4.5 & 1.5 & -4.5 & 1.5 \\
\hline \multirow[t]{2}{*}{ Facility 1} & units (\%) & $\begin{array}{l}-0.001 \\
(-0.03)\end{array}$ & $\begin{array}{l}-0.2 \\
(-1.9)\end{array}$ & $\begin{array}{l}0.05 \\
(1.2)\end{array}$ & $\begin{array}{l}-0.08 \\
(-0.7)\end{array}$ & $\begin{array}{l}-0.04 \\
(-0.9)\end{array}$ & $\begin{array}{l}0.46 \\
(4.0)\end{array}$ \\
\hline & $\begin{array}{l}\text { Temperature } \\
(\mathrm{K}) \\
(q=20 \mathrm{~W} / \mathrm{m})\end{array}$ & -0.001 & -0.02 & 0.07 & -0.03 & -0.05 & 0.5 \\
\hline \multirow[t]{2}{*}{ Facility 2} & units (\%) & $\begin{array}{l}-0.02 \\
(-0.6)\end{array}$ & $\begin{array}{l}-0.15 \\
(-1.1)\end{array}$ & $\begin{array}{l}0.04 \\
(1.2)\end{array}$ & $\begin{array}{l}-0.03 \\
(-0.3)\end{array}$ & $\begin{array}{l}-0.0006 \\
(-0.02)\end{array}$ & $\begin{array}{l}0.62 \\
(4.7)\end{array}$ \\
\hline & $\begin{array}{l}\text { Temperature } \\
(\mathrm{K}) \\
(q=20 \mathrm{~W} / \mathrm{m})\end{array}$ & -0.05 & -0.29 & 0.09 & -0.07 & -0.001 & 1.23 \\
\hline
\end{tabular}

The comparison of the TRFs-'FEM - EHCM' and the TRFs- 'FLS - Uniform Temperature' presents a similar behavior as observed in Fig. 3. At $\ln \left(\mathrm{t} / \mathrm{t}_{\mathrm{s}}\right)=-4.5$, the TRF-'FEM - EHCM' present slightly lower values (1.2\%) as compared to the TRF-'FLS - Uniform 
Temperature' . Whereas, the TRF-'FLS - Uniform Temperature' results in lower values (varying between 0.3 and $0.7 \%$ ) at $\ln \left(t / t_{s}\right)=-4.5$. The lesser deviations observed for the $4 \times 4$ bore field in Section 4.2 when comparing the TRF-'FEM - EHCM' and the TRF- 'FLS Uniform Temperature' are associated with the size of the triangular elements at top layer (below the inactive upper part of the bore field) that the computer can handle without compromising its computational capability. The $4 \times 4$ bore field has a smaller computing domain (one-eighth against one-quarter) than the remaining bore field geometries. Moreover, the disposition of the boreholes in the $4 \times 4$ bore field results in lesser element growth of the mesh, i.e. finer mesh elements.

In Figs. 11 and 12 for both bore field geometries, a similar behavior is observed among the TRFs considered in this study except for the TRF-'FDM - Uniform Temperature'. For In $\left(t / t_{s}\right)<0$, TRFs based on the finite difference approach with uniform temperature condition at the borehole wall present higher values than the other solutions studied in this paper. For example, at $\ln \left(t / t_{s}\right) 0=-4.5$, the difference between the TRF- 'FDM Uniform Temperature' and TRF- 'FEM - EHCM' are 0.16 and 0.12 units for the TRFs in Figs. 1 and 7, respectively; these differences increase to 0.21 and 0.19 in Figs. 11 and 12. For In $\left(t / t_{s}\right)>0$, TRF- 'FDM - Uniform Temperature' overestimates the response for the cases studied in Figs. 1 and 7 as have been analyzed above. However, the comparison of the TRF - 'FDM - Uniform Temperature' against solutions based on the same boundary condition showed opposite results in Figs. 11 and 12 . While the TRF - 'FDM - Uniform Temperature' in Fig. 11 tends to overestimate the response and presents a closer behavior to the TRF based on a constant heat flux boundary condition, the TRF - 'FDM - Uniform Temperature' in Fig. 12 results in a smaller response as compared to solutions based on the same boundary condition. For example, in Fig. 11, at $\ln \left(\mathrm{t} / \mathrm{t}_{\mathrm{s}}\right)=1.5$, TRF- 'FDM - Uniform Temperature' deviates 0.46 units from the TRF'FEM - EHCM' . In Fig. 12, TRF- 'FDM - Uniform Temperature' differs from the TRF - 'FEM - EHCM' by -0.11 units.

In Fig. 11, the deviations observed in the TRF - 'FDM Uniform Temperature' are attributed to the aspect ratio $\mathrm{D} / \mathrm{H}$ (actual aspect ratio of $\mathrm{D} / \mathrm{H}$ vs the input value of $D(4$ or $5 \mathrm{~m}$ ) in the software) and to the mesh. The differences in the TRF - 'FDM - Uniform Temperature' observed in Fig. 12 are attributed to the incorrectness of the finite difference solution to account for the effect of the upper inactive part in shallower boreholes $(<100 \mathrm{~m})$.

These comparisons showed that the TRF - 'FDM - Uniform Temperature' reported in this study, which are embedded in the library of the g-function of commercial software programs, differ from solutions based on the same boundary condition and from more advanced solutions (i.e. EHCM and [4]). Although these differences are not relevant for the bore field configurations studied in this paper and at the designed lifetime span of these systems, a revision of the TRFs embedded in the library of the design tools is recommended.

Apart from this observation, at short times when $\ln \left(t / t_{s}\right)<-2$, the TRFs obtained from all the other approaches present very similar behavior as observed in Figs. 1 and 12. The 
deviations among the TRFs with different boundary conditions, as discussed in Section 4, will not be of importance until borehole thermal interactions and axial heat transfer becomes important.

\subsection{Fluid temperature prediction and comparison with measured data}

Inlet and outlet temperatures and mass flow measurements of the GHE circuit have been monitored at intervals of $10 \mathrm{~min}$ in 'Facility $1^{\prime}$ ', while data is logged at 20 s intervals in 'Facility 2'. The heat flow exchanged with the ground is obtained from the inlet and outlet temperatures, the mass flow and the thermal properties of the secondary fluid. For the present study, the heat flow and temperature measurements are grouped in daily steps. The daily measured heat flows correspond to the measured daily loads that are given as input the numerical model. Positive heat flow values represent heat extraction, while injection of heat is represented by negative values.

As shown in Table 1, the monitored period of 'Facility 1' corresponds to 3 years and 11 months, whereas 'Facility 2 ' is being monitored from the beginning of its operation up to now, at this study the analysis is done for around 10 years. In 'Facility 1 ', there were some periods that lack recorded data. Further details about the monitoring activities in' Facility 1 'can be found in Puttige et al. [27]. In 'Facility 2' the profile load from January 2005 to December 2010 is similar to the one utilized in the previous study presented in Monzó et al. [23] and the profile load is completed until June 2015 with the measurements from Ruiz-Calvo et al. [31].

Figs. 13 and 14 present the comparison of measured daily temperatures and simulated daily fluid temperatures for 'Facility 1 ' and 'Facility 2', respectively. The simulated temperatures are obtained from the EHCM model, the previous HCM Model and from the aforementioned model of FEM with constant heat flux boundary condition at the borehole wall, which are labeled 'Simulated Daily Temp FEM-EHCM', 'Simulated Daily Temp FEM-HCM' and 'Simulated Daily Temp FEM-QC' respectively. The measured daily fluid temperatures are labeled 'Measured Daily Temp' and the load profile is referred to the secondary y-axis tagged 'Daily Average Heat Flow' are also shown in Figs. 13 and 14. 


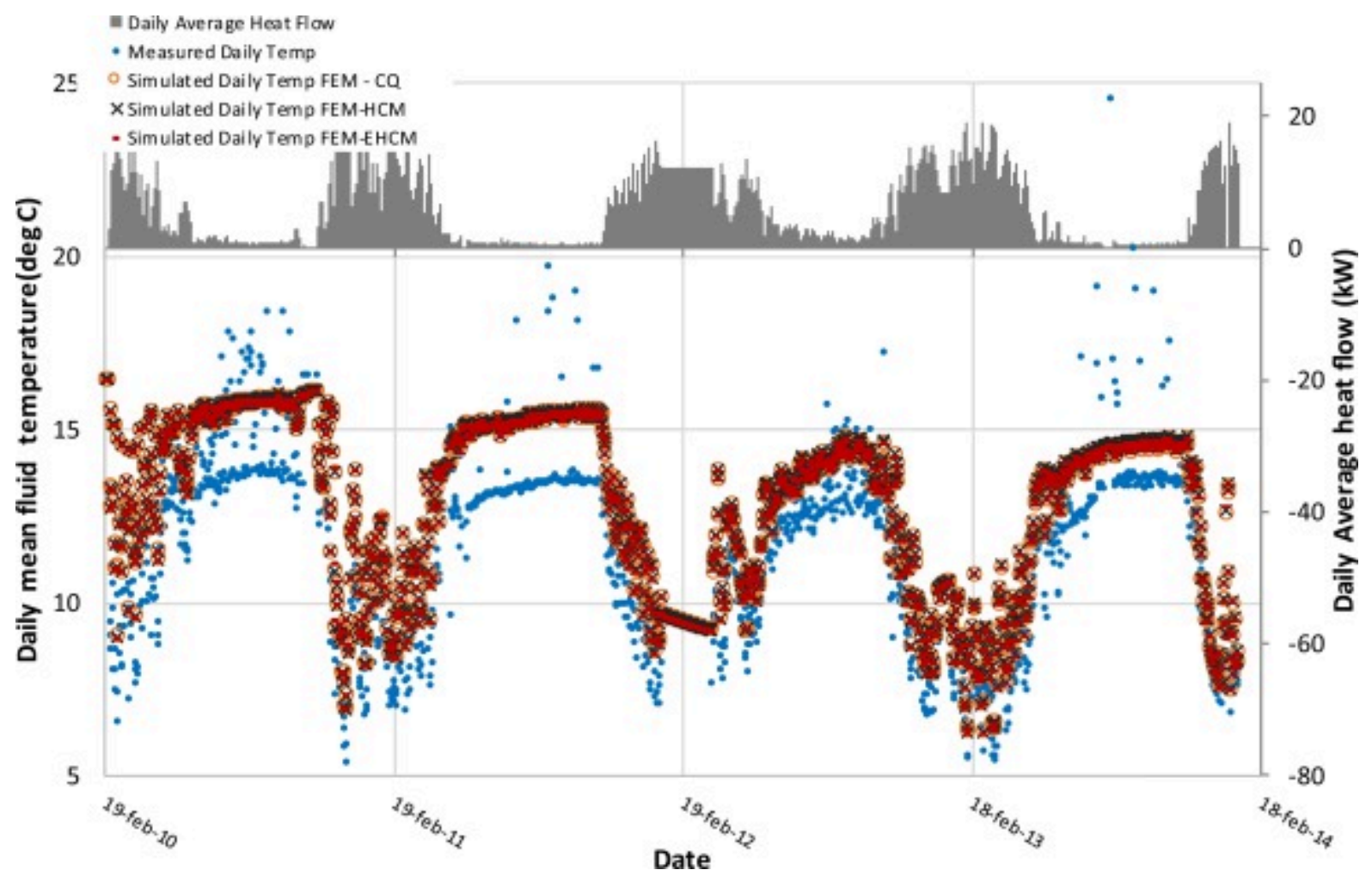

Fig. 13. Daily fluid temperature predictions using FEM models and comparison with measured data for 'Facility 1 '.

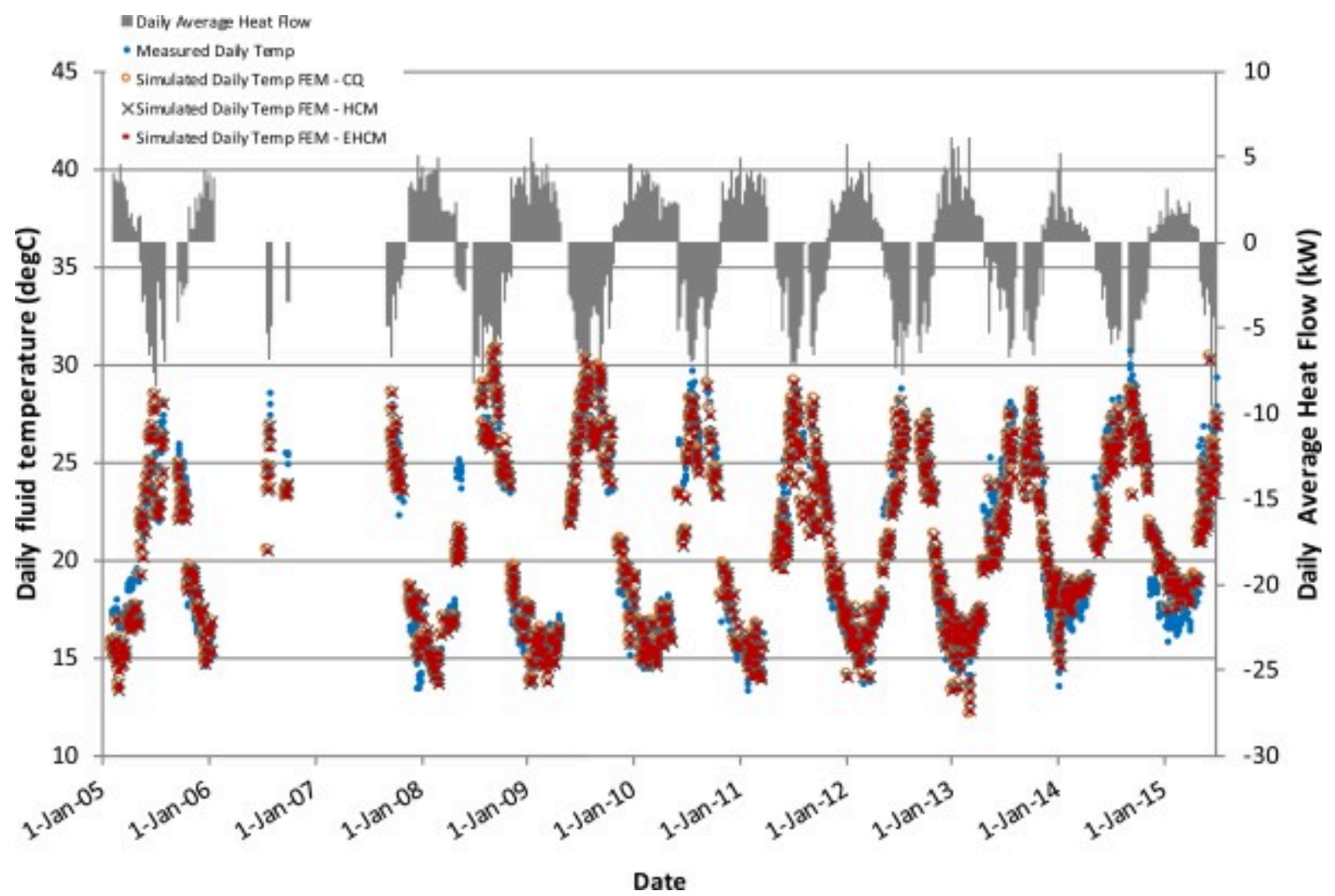

Fig. 14. Daily fluid temperature predictions using FEM models and comparison with measured data for 'Facility 2'. 
The deviation of 'Simulated Daily Temp FEM-EHCM' against 'Measured Daily Temp' in 'Facility 1 ' presents a mean absolute error (MAE) of $1.6 \mathrm{~K}$, a mean bias error (MBE) of $1.4 \mathrm{~K}$ and a root mean square error (RMSE) of $1.8 \mathrm{~K}$ for the entire period. In Figs. 13, it can be observed that in the first two years the deviations of predicted against measured temperatures are higher as indicated by an MAE of $1.8 \mathrm{~K}$ and an RMSE of $2 \mathrm{~K}$, whereas the MAE and RMSE for the last year are $1.2 \mathrm{~K}$ and $1.5 \mathrm{~K}$, respectively. These differences are partly explained by the unrecorded test performed during January 2010, which was not considered in the simulation. The maximum deviation in 2010 occurs in the first few days. A procedure based on the TRFs and the temperature difference between the undisturbed ground temperature and the first measured temperatures was used to quantify the effect of the test performed in January 2010, as described in Puttige [26]. The total MAE and RMSE for the whole period are reduced by $13 \%$ and $11 \%$ respectively when the influence of the operation in January 2010 is taken into account. Except for the deviation observed during the first year, in the remaining years the maximum deviation occurs in summer where some odd high temperatures are observed. Since the raw measured data is obtained from momentary points taken every 10 min and the response time of temperature sensors are typically much longer than the response time of flow meters, a measurement recorded in the time frame between the response time of the flow meters and the temperature sensors would explain the observed odd high temperatures. Such readings are more likely to occur in summer because the flow in the boreholes occurs for shorter durations in summer as the load is lower. Hence these points do not represent the fluid temperature in the borehole.

With regard to the predictions from the distinct models in Fig. 13, there are no significant differences between them. The overall analysis of the simulated temperatures obtained from the EHCM model, the HCM model and the FEM model with constant heat flux boundary condition at the borehole wall against measured data, shows that the predictions from the EHCM model are closer to the measured data. However, the deviations among the models are not significant, in the order of $10^{-2} \mathrm{~K}$. The order of the deviation between the EHCM model and the HCM model can be estimated using their TRFs. For the time period analyzed, which corresponds to $\ln \left(t / t_{s}\right)=-2.3$ for input parameters in 'Facility 1 ' and its monitored period, the deviation of the TRF is 0.03 units. Then, if we consider a constant heat load of $8.75 \mathrm{~W} / \mathrm{m}$, which corresponds to the average ground load in 'Facility 1 ' for the period analyzed, the 0.03 units difference between the responses in terms of temperature is $0.01 \mathrm{~K}$. So, the deviation of the models is of the same order of magnitude as the deviation of the predictions against measured temperatures. Therefore, the magnitude of reduction in error between the models is too small to conclusively state that the fluid temperature predictions are better in the EHCM model.

In 'Facility 2', Fig. 14, the comparison of 'Simulated Daily Temp EHCM' with respect to the measured data results in an MAE of $1.1 \mathrm{~K}$, an MBE of $0.2 \mathrm{~K}$ and an RMSE of $1.4 \mathrm{~K}$ for the whole period. The MAE relative to heating and cooling periods is around $1-1.1 \mathrm{~K}$ with slightly lower deviation in heating periods. In general, the models tend to underestimate the fluid temperatures in either heating or cooling conditions with similar 
deviations in both operating modes. This observation corrects the statement about higher deviations in cooling mode found in the previous investigation [23]. The highest deviation occurs in 2015 with an MAE around 1.9 K (RMSE 2.1 K) followed by the predictions in 2014 with an MAE of 1.4 K (RMSE 1.7 K). During 2014 and 2015, the recorded loads for heating are visibly lower than the other years and fluid temperatures also reflect this fact. No evidence could be found to explain the deviations during this period. The predicted values in 2009 and 2012 present a low MAE, which is around $0.75 \mathrm{~K}$ and an RMSE of $1 \mathrm{~K}$.

As in the analysis of 'Facility 1 ', the predictions in 'Facility 2' obtained from the distinct models result in very similar responses with no significant deviations (in the order of $10^{-3} \mathrm{~K}$ ) between them. With regard to the improvements applied to the HCM model, the average absolute error of HCM model with respect to EHCM model is $0.026 \mathrm{~K}$. The difference between the TRFs obtained from the HCM model and EHCM model is 0.115 units at $\ln \left(t / t_{s}\right)=-0.06$, which corresponds to10.5 years at 'Facility 2 '). In terms of temperature, this deviation is about $0.021 \mathrm{~K}$ when a load equal to the net total imbalance is assumed (24.7 MWh of cooling load). The average absolute error of the predicted fluid temperature with constant heat flux boundary condition ('Simulated Daily Temp FEM CQ') in comparison to the predictions from the EHCM model is $0.04 \mathrm{~K}$, which increases to $0.09 \mathrm{~K}$ for the predictions in 2015. The approximate difference between the models after the 10.5 years is estimated using the TRFs, which results in a temperature difference of around $0.08 \mathrm{~K}$ when the $24.7 \mathrm{MWh}$ of cooling imbalance of the system is considered. Thus, the difference between the TRFs of the models is of the same order as the difference between the predicted values and the fluid temperature measurements.

The analyses of the predicted temperatures against measured values in both 'Facility 1' and 'Facility 2' show that although predictions from the EHCM model present closer agreement than the other considered approaches, the magnitude of reduction in error between the models is too small to conclusively state that the fluid temperature predictions are better in the EHCM model. It is important to note that the predictions resulting from the models are also subject to errors in experimental measurements.

\section{Conclusions}

Two simultaneous boundary conditions are usually applied to mathematical approaches of ground heat exchangers connected in parallel: a total bore field heat flow (equal to the thermal power required by the heat pump) and a uniform temperature boundary condition at all the borehole walls. However, the fact that there is a borehole thermal resistance between the fluid and the borehole wall and that the heat flux increases at the borehole ends result in temperature changes between the borehole wall and the fluid. Thus the borehole wall temperature deviates from the uniform assumption and will cause an error in the simulations. This paper describes improvements applied to a previous numerical approach, in which the temperature response of the ground is modeled when a total thermal power is imposed through a set of boreholes connected in parallel. The model is developed for a $2 \times 3$ and a $4 \times 4$ bore field. The improvements 
are applied to take into account the effect of the fluid-to-borehole thermal resistance on the thermal response at the borehole wall. The improved model is validated for the generation of the temperature response functions when a total constant heat flow is imposed in the bore field. Although no relevant deviations are observed in the TRFs resulting from the proposed numerical model when compared with reference solutions obtained from a uniform temperature boundary condition at the borehole wall, the improvements applied to the previous numerical model correct the response at the borehole wall and the heat flow distribution among the boreholes. Deviations increase with number of boreholes, which can have a significant impact when modeling large multiple bore fields. An analysis is performed to evaluate the influence of the GHE thermal resistance on the temperature and heat flux along borehole wall. The error of the proposed model for the post-calculation of the total heat flow is around $0.6 \%$ for transient solutions and $0.01 \%$ for steady-state solutions.

The improved model is also utilized to illustrate daily fluid temperature predictions for variable measured daily loads of two monitored GCHP facilities. The predictions from the improved model are compared against measured data and predictions from reference approaches. The predicted temperature against measured values in both monitored facilities show that predictions from the improved model present closer agreement than the other considered approaches, however, the magnitude of reduction in error between the models is too small to conclusively state that the fluid temperature predictions are better in the improved model, taking into account the uncertainties in the measurements. The accuracy of the proposed model to predict fluid temperature according to the analysis against measured data is with an MAE (RMSE) between 1.1 and $1.6 \mathrm{~K}(1.4$ and $1.8 \mathrm{~K}$, respectively).

\section{Acknowledgements}

The Swedish Energy Agency is acknowledged for financing this project. The authors thank Massimo Cimmino (École Polytechnique de Montréal, Canada) for contributing to the generation of a particular solution with his approach.

\section{References}

[1] J. Acuña. Distributed Thermal Response Tests: New Insights on U-pipe and Coaxial Heat Exchangers in Groundwater-Filled Boreholes. PhD Thesis Dept. of Energy Technology, KTH Royal Institute of Technology, Sweden (2013)

[2] M. Bernier. Sizing and simulating geothermal bore fields using thermal response factors, 11th IEA Heat Pump Conference 2014, Canada, (2014) KN3.1.1

[3] M. Cimmino. Fluid and borehole wall temperature profiles in vertical geothermal boreholes with multiple U-tubes. Renew. Energy, 96 (Part A) (2016), pp. 137-147

[4] M. Cimmino. The effects of borehole thermal resistances and fluid flow rate on the g-functions of geothermal bore fields. Int. J. Heat Mass Transf., 91 (2015), pp. 1119-1127

[5] M. Cimmino, M. Bernier. Experimental determination of the g-functions of a small-scale geothermal borehole. Geothermics, 56 (2015), pp. 60-71 
[6] M. Cimmino, M. Bernier. A semi-analytical method to generate g-functions for geothermal bore fields. Int. J. Heat Mass Transf., 70 (2014), pp. 641-650

[7] M. Cimmino, M. Bernier. Preprocessor for the generation of g-functions used in the simulation of geothermal systems, Proceedings, 13th Conference of International Building Performance Simulation Association, France, (2013), pp. 2675-2682

[8] J. Claesson, S. Javed. An analytical method to calculate borehole fluid temperatures for time-scales from minutes to decades. ASHRAE Trans., 117 (2) (2011), pp. 279-288

[9] J.M. Corberan, D.P. Finn, C.M. Montagud, F.T. Murphy, K.C. Edwards. A quasi-steady state mathematical model of an integrated ground source heat pump for building space control. Energy Build., 43 (2011), pp. 82-92

[10] P. Eskilson. Superposition borehole model. Manual for Computer Code, Dept. of Mathematical Physics, Lund Institute of Technology, Lund, Sweden (1986)

[11] P. Eskilson. Thermal Analysis of Heat Extraction Boreholes. Ph.D. Thesis Dep. of Mathematical Physics, University of Lund, Sweden (1987)

[12] M. Fossa. The temperature penalty approach to the design of borehole heat exchangers for heat pump applications. Energy Build., 43 (2011), pp. 1473-1479

[13] Ground-Med. D.6.5: University Polytechnic of Valencia demo system in Spain. Work Package 6: Integrated Ground Source Heat Pump Demonstration Systems. Seventh FP No TREN/FP7EN/218895 http://www.groundmed.eu/uploads/media/Deliverable_6.5_UPV_demo_system_ 01.pdf (2011) 26/05/2017

[14] G. Hellström, B. Sanner. Earth Energy Designer: software for dimensioning of deep bore holes for heat extraction, Proc. Calorstock - 6th Int. Conference on Thermal Energy Storage, Finland, (1994), pp. 195-202

[15] M. Iglesias, J. Rodríguez, D. Franco. Monitoring of building heating and cooling systems based on geothermal heat pump in galicia (Spain). EPJ Web Conf., 33 (2012), p. 05004

[16] S. Javed, J.D. Spitler. 3 - Calculation of borehole thermal resistance A2 - Rees. J. Simon (Ed.), Advances in Ground-Source Heat Pump Systems, Woodhead Publishing, (2016), pp. 63-95

[17] L. Lamarche, B. Beauchamp. A new contribution to the finite line-source model for geothermal boreholes. Energy Build., 39 (2007), pp. 188-198

[18] A. Lazzarotto. A methodology for the calculation of response functions for geothermal fields with arbitrarily oriented boreholes - part 1. Renew. Energy, 86 (2016), pp. 1380-1393

[19] C.K. Lee, H.N. Lam. Computer simulation of borehole ground heat exchangers for geothermal heat pump systems. Renew. Energy, 33 (2008), pp. 1286-1296

[20] C.L. Marshall, J.D. Spitler. GLHEPRO -The Professional Ground Loop Heat Exchanger Design Software. Users guide, School of Mechanical and Aerospace Engineering, Oklahoma State University, Oklahoma (1994)

[21] C. Montagud, J.M. Corberán, Á. Montero, J.F. Urchueguía. Analysis of the energy performance of a ground source heat pump system after five years of operation. Energy Build., 43 (2011), pp. 3618-3626

[22] P. Monzó, J. Acuna, M. Fossa, B. Palm. Numerical generation of the temperature response factors for a borehole heat exchanger field, European Geothermal Congress 2013, Italy, (2013) 
[23] P. Monzó, P. Mogensen, J. Acuña, F. Ruiz-Calvo, C. Montagud. A novel numerical approach for imposing a temperature boundary condition at the borehole wall in borehole fields. Geothermics, 56 (2015), pp. 35-44

[24] A. Priarone, M. Fossa. Temperature response factors at different boundary conditions for modelling the single borehole heat exchanger. Appl. Therm. Eng., 103 (2016), pp. 934-944

[25] A. Priarone, M. Fossa. Modelling the ground volume for numerically generating single borehole heat exchanger response factors according to the cylindrical source approach. Geothermics, 58 (2015), pp. 3238

[26] A.R. Puttige. Improvements on HCM Model for g-Function Generation and Illustration of Fluid Temperature Prediction, MSc. Thesis Dept. of Energy Tech., KTH Royal Institute of Technology, Sweden (2016)

[27] A.R. Puttige, J. Rodriguez, P. Monzó, F. Cerdeira, A. Fernández, L. Novelle. Improvements on a numerical model of borehole heat exchangers, European Geothermal Congress 2016, France, (2016)

[28] E. Zanchini, S. Lazzari, A. Priarone. Long-term performance of large borehole heat exchanger fields with unbalanced seasonal loads and groundwater flow. Energy, 38 (2012), pp. 66-77

[29] H.Y. Zeng, N.R. Diao, Z.H. Fang. A finite line-source model for boreholes in geothermal heat exchangers. Heat Transfer Asian Res, 31 (2002), pp. 558-567

[30] H. Zeng, N. Diao, Z. Fang. Heat transfer analysis of boreholes in vertical ground heat exchangers. Int. J. Heat Mass Transfer, 46 (2003), pp. 4467-4481

[31] F. Ruiz-Calvo, J. Cervera-Vázquez, C. Montagud, J.M. Corberán. Reference data sets for validating and analyzing GSHP systems based on an eleven-year operation period. Geothermics, 64 (2016), pp. 538-550 